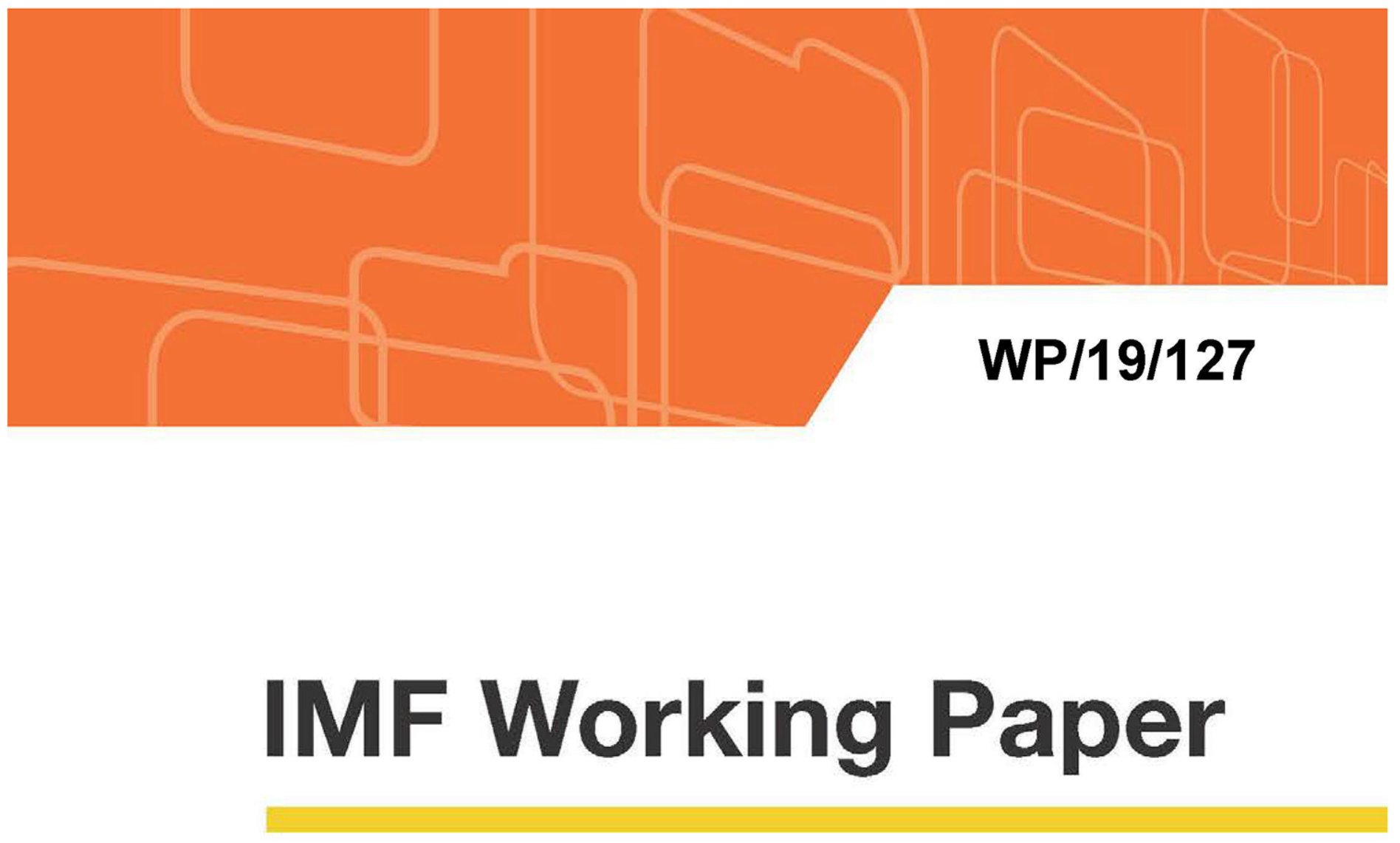

\title{
From Basel I to Basel III: Sequencing Implementation in Developing Economies
}

by Caio Ferreira, Nigel Jenkinson, and Christopher Wilson

IMF Working Papers describe research in progress by the author(s) and are published to elicit comments and to encourage debate. The views expressed in IMF Working Papers are those of the author(s) and do not necessarily represent the views of the IMF, its Executive Board, or IMF management. 


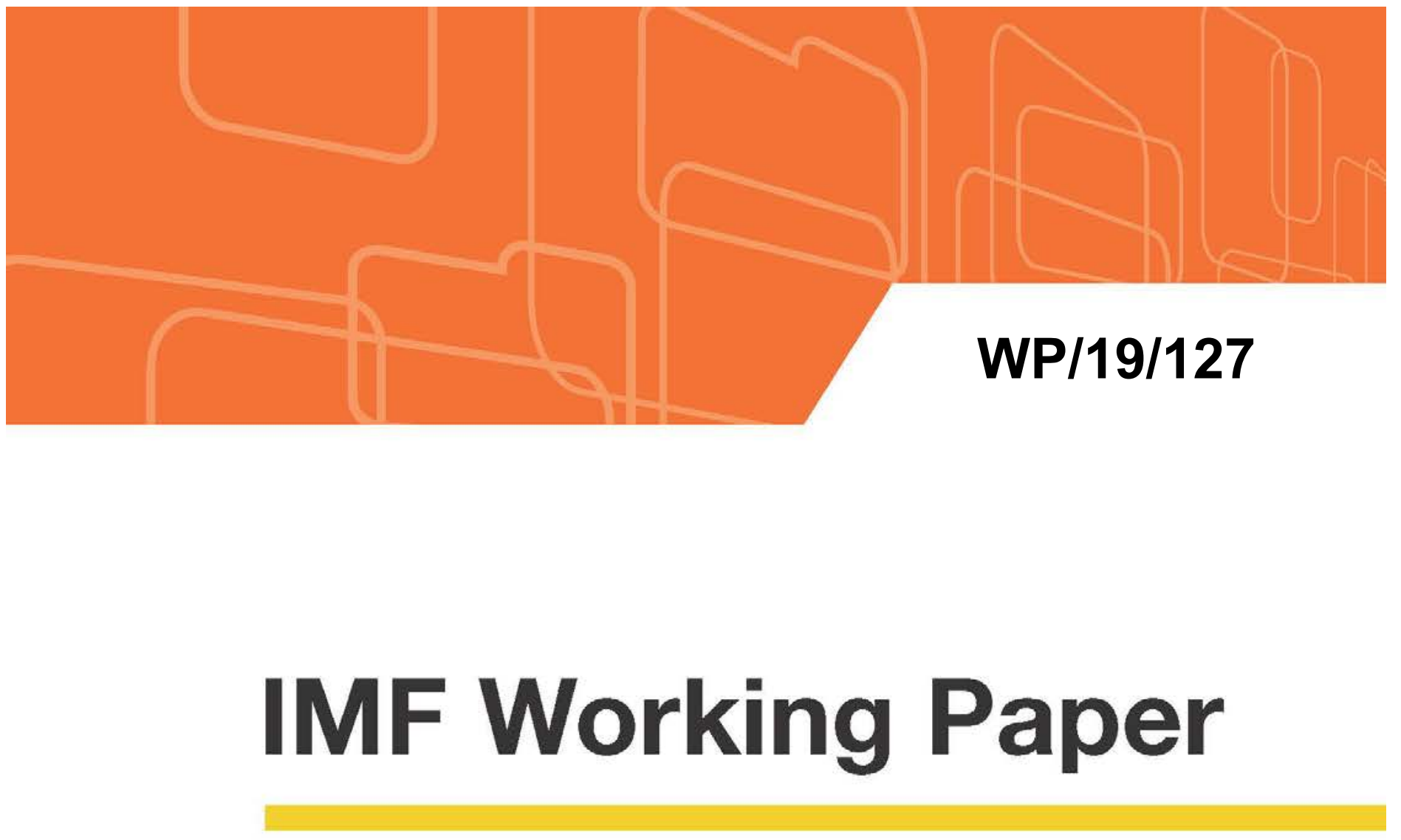

\section{From Basel I to Basel III: Sequencing Implementation in Developing Economies}

by Caio Ferreira, Nigel Jenkinson, and Christopher Wilson

IMF Working Papers describe research in progress by the author(s) and are published to elicit comments and to encourage debate. The views expressed in IMF Working Papers are those of the author(s) and do not necessarily represent the views of the IMF, its Executive Board, or IMF management. 


\title{
IMF Working Paper
}

Monetary and Capital Markets Department

From Basel I to Basel III:

Sequencing Implementation in Developing Economies

\section{Prepared by Caio Ferreira, Nigel Jenkinson, and Christopher Wilson}

Authorized for distribution by Aditya Narain

June 2019

IMF Working Papers describe research in progress by the author(s) and are published to elicit comments and to encourage debate. The views expressed in IMF Working Papers are those of the author(s) and do not necessarily represent the views of the IMF, its Executive Board, or IMF management.

\begin{abstract}
Developing economies can strengthen their financial systems by implementing the main elements of global regulatory reform. But to build an effective prudential framework, they may need to adapt international standards taking into account the sophistication and size of their financial institutions, the relevance of different financial operations in their market, the granularity of information available and the capacity of their supervisors. Under a proportionate application of the Basel standards, smaller institutions with less complex business models would be subject to a simpler regulatory framework that enhances the resilience of the financial sector without generating disproportionate compliance costs. This paper provides guidance on how non-Basel Committee member countries could incorporate banks' capital and liquidity standards into their framework. It builds on the experience gained by the authors in the course of their work in providing technical assistance on - and assessing compliance with - international standards in banking supervision.
\end{abstract}

JEL Classification Numbers: G21; G28

Keywords: Banks, Banking crisis, Basel Accords, Capital Requirements, Liquidity Requirements, Supervision

Author’s E-Mail Address: cferreira@imf.org; njenkinson@imf.org; cwilson@imf.org 


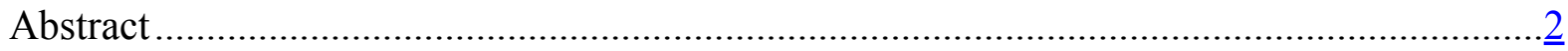

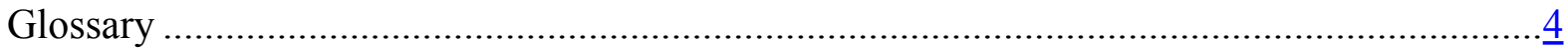

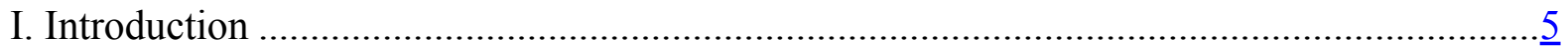

II. Establishing the Priorities: The Basel Core Principles for Effective Banking Supervision..7

A. Effective Implementation of the International Standards ...............................

III. Capital Requirements ....................................................................................... 11

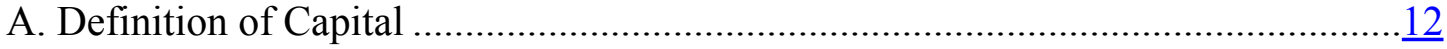

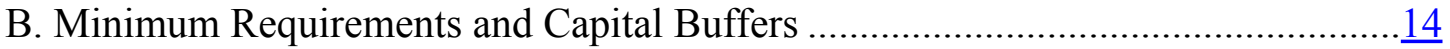

C. Risk-Weighted Assets .......................................................................... $\frac{18}{22}$

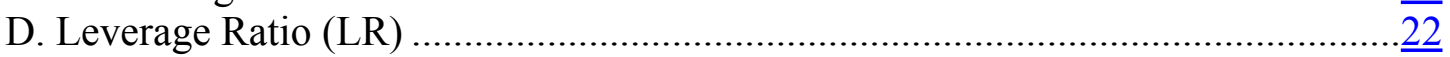

E. The Second and Third Pillars ........................................................................... 24

F. Interest Rate Risk in the Banking Book (IRRBB) .........................................

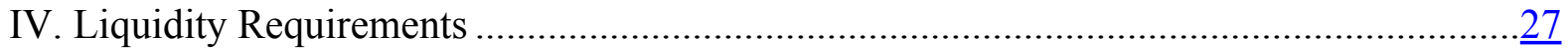

A. Liquidity Coverage Ratio (LCR) …….................................................... $\frac{27}{31}$

B. Net Stable Funding Ratio (NSFR) ............................................................

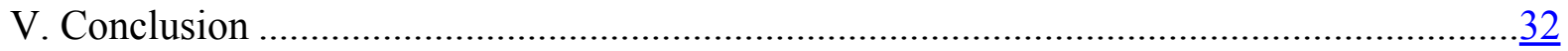

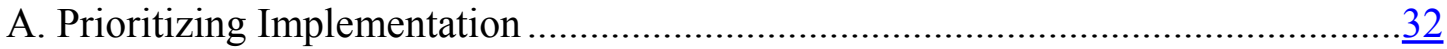

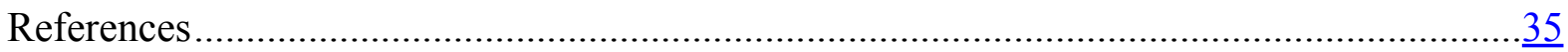

Figures

1. Adoption of Banking Standards among Non-Basel Committee Members ........................13

2. Comparison of Basel II and Basel III Capital Requirements....................................... $\frac{15}{33}$

3. Possible Priority for Implementation of Basel Prudential Standards............................... $\underline{33}$

Boxes

1. A Bird's Eye View of the Regulatory Reforms .......................................................

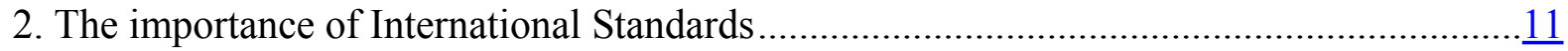

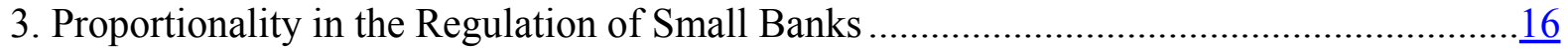

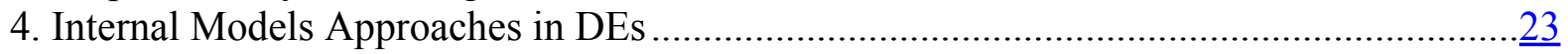

5. Principles for Sound Liquidity Risk Management and Supervision................................ $\underline{30}$

6. Prudential Regulation and Market Development.....................................................

Appendices

1. Basel III Capital Structure Implementation Steps ....................................................... $\underline{39}$

2. Guiding Principle for Modifying LCR and Main Issues .......................................... $\underline{40}$ 


\section{GLOSSARY}

\begin{tabular}{|c|c|}
\hline $\mathrm{AE}$ & Advanced Economies \\
\hline BCP & Basel Core Principles for Effective Banking Supervision \\
\hline BCBS & Basel Committee on Banking Supervision \\
\hline CAMELS & Capital adequacy, Asset quality, Management, Earnings, and Liquidity \\
\hline $\mathrm{CCF}$ & Credit Conversion Factor \\
\hline D-SIB & Domestic Systemically Important Bank \\
\hline DEs & Developing Economies \\
\hline FSAP & Financial Sector Assessment Program \\
\hline FSB & Financial Stability Board \\
\hline GFC & Global Financial Crisis \\
\hline G-SIB & Global Systemically Important Bank \\
\hline HQLA & High-Quality Liquid Asset \\
\hline ICAAP & Internal Capital Adequacy Assessment Process \\
\hline IMF & International Monetary Fund \\
\hline IRB & Internal Ratings-Based Approach \\
\hline IRRBB & Interest Rate Risk in the Banking Book \\
\hline LCR & Liquidity Coverage Ratio \\
\hline LR & Leverage Ratio \\
\hline NSFR & Net Stable Funding Ratio \\
\hline QIS & Quantitative Impact Study \\
\hline RBS & Risk-Based Supervision \\
\hline RWA & Risk-Weighted Assets \\
\hline SIB & Systemically Important Bank \\
\hline SME & Small- and medium-sized enterprises \\
\hline SRP & Supervisory Review Process \\
\hline
\end{tabular}




\section{INTRODUCTION ${ }^{1}$}

The Global Financial Crisis (GFC) spurred an unprecedented review of international prudential standards. In response to the crisis, the international community launched a major reform program aiming to address the fault lines at the source of the crisis. These flaws included regulatory and oversight system deficiencies; inappropriate incentives for bank and risk managers; flaws in techniques used to measure, price, and manage risks; and corporate governance weaknesses that hindered proper monitoring of banks' risks, as well as maintenance of ethical integrity. The reforms addressed these regulatory weaknesses and substantially strengthened the financial system (Box 1).

While the reforms provided an essential response to regulatory weaknesses, they focused primarily on large internationally active financial institutions and complex financial markets. The membership of international standard setters has been expanded to encompass some important emerging markets. This expansion has helped enhance the global reach of the international standards. However, the relative importance of internationally active banks and advanced economies for global financial stability, and the immediate source of the problems that were being addressed, guided the technical discussions and political compromises that led to the new standards. As a result, the full set of the international standards may not always be applicable to less complex and smaller financial markets, whose financial systems and supervisory capacity are still developing. At the same time, the principles underlying these standards remain relevant for all, as they provide important directions and considerations to be taken in to account in crafting the approaches to their implementation.

The new international standards provide a good basis for strengthening the financial systems in developing economies (DEs). ${ }^{2}$ While the origins of the GFC and its direct impact was concentrated mainly on advanced economies, it provided lessons that can be drawn on by DEs to avoid similar setbacks. A lack of high quality and appropriate levels of capital and excessive leverage, issues that to some extent have already been identified and addressed in many DEs, were some of the regulatory weaknesses that became clear during the crisis. However, there are several issues that DEs still need to tackle which were highlighted by the GFC, including the importance of: (i) liquidity buffers to avoid destabilizing fire sales and the need for early intervention by public authorities; (ii) a greater system-wide or macroprudential approach to regulation and supervision to help safeguard financial stability; (iii) efforts to make systemically important institutions resolvable to mitigate moral hazard and avoid costly bail outs; (iv) sound corporate governance and risk management to help ensure the proper functioning of the banking

\footnotetext{
${ }^{1}$ The authors are grateful to Daniel Tarullo, Willian Coen, Aditya Narain, Alejandro Lopez Mejia, Fabiana Melo, Jennifer Elliott, Antonio Pancorbo, Dirk Jan Grolleman, Hee Kyong Chon, Luc Riedweg, Kate Seal, Nobuyasu Sugimoto, Pierpaolo Grippa, Rachid Awad, and participants in the MCM Policy Forum for many helpful comments on an earlier draft.

${ }^{2}$ The term developing economies (DE) is used in this paper to designate those countries with less developed financial systems typical to the low-income country classification as applied by the IMF. Advanced economies and emerging market countries that are members of the Basel Committee members have committed to fully implement the standards (see discussion in Box 2). However, the discussion of proportionality in this paper would also apply to smaller banks with simpler business models in these jurisdictions as well.
} 
sector; and (v) a legal and operational framework for financial sector oversight to allow supervisors to take corrective measures at an early stage, even when no minimum regulatory threshold has been breached.

To build an effective prudential framework, DEs can consider their specific characteristics when implementing international standards. DEs are a large and heterogeneous group of countries whose financial systems differ among each other and from those in advanced economies. Broadly speaking, financial systems of many DEs are still deepening and are composed of relatively smaller and simpler institutions. Financial market infrastructure also tends to be less developed and the institutional framework less mature. In this context, the simple transposition of international standards designed primarily from the experience of more advanced financial markets might lead to inadequate prudential buffers, compliance costs not commensurate with the benefits of implementation, challenges to the enforcement of regulation, inappropriate economic incentives, and, ultimately, an ineffective regulatory framework. DEs could thus consider adapting the international standards to the sophistication and size of their financial institutions, the relevance of different financial operations in their market, the granularity of information available and the capacity of their supervisors (see Box 2 for a broader discussion on tailoring of international standards).

The following guiding principles should guide any such adaptation:

- Rigor: Although international standards may need to be adapted to better suit DEs, changes should not lead to less rigorous prudential frameworks that lead to less resilient financial institutions or promote riskier behavior.

- Context: Furthermore, the regulatory framework must take into account the features of the risk environment that could be more pronounced, such as market illiquidity, high volatility, and challenges to the enforcement of claims and the execution of collateral.

- Scope: While the characteristics of their financial systems may favor simpler standards, authorities should not compromise on the scope of regulation and must take in to account the fundamental regulatory weaknesses identified during the financial crisis.

- Evolution: In adapting the standards and phasing in their implementation, it must be kept in mind that as financial systems deepen and become more complex, the regulatory framework will also need to support convergence to international practices.

- Effectiveness: While the full set of international standards may not always be applicable to less complex and smaller financial markets, the underlying preconditions and expectations of the Basel Core Principles (BCP) for Effective Banking Supervision should be met.

This paper provides practical guidance on how DEs could incorporate international standards into their prudential framework. The paper builds on the extensive experience gained on technical assistance missions on banking supervision and regulation that the IMF provides every year to more than 70 countries as well as from the Financial Sector Assessment Program (FSAP), 
which has undertaken some 280 detailed assessments of banking supervision in over 160 jurisdictions since its inception in $1999 .{ }^{3}$ Considering the dominance of banks in the financial system of most DEs, the paper focuses on banking regulatory and supervisory issues. Section II discusses how the Basel Core Principles for Effective Banking Supervision (BCP) can be used to set appropriate priorities for improving banking sector oversight. The BCP provide high-level principles that have proved to be useful when adapting and implementing international standards in many DEs from the IMFs membership. Sections III and IV discuss the enhanced capital and liquidity prudential requirements, which have been developed post-GFC, respectively. Finally, Section V discusses priorities when moving from Basel I to Basel III.

\section{Establishing the Priorities: The Basel Core Principles for Effective Banking SUPERVISION}

Increasing the resilience of the financial system requires a sound oversight framework that goes well beyond the implementation of the latest Basel capital standards. The GFC revealed weaknesses both in the regulatory and supervision frameworks. Often supervisory powers, resources, processes, and requirements were insufficient to allow an appropriate assessment of risks and timely action to address unsustainable practices. Further, the supervisory approach had become increasingly laissez-faire and "light touch" while often maintaining an implicit public-sector guarantee of the banking sector. The post-crisis consensus is that supervision needs to be more comprehensive and intrusive (BCBS, 2015b; and FSB, 2010). As IMF (2010) puts it, good supervision requires learning to say "no."

The BCP for Effective Banking Supervision have served as the key tool to identify priorities and enhance the banking oversight framework of countries. The BCP are a framework of minimum standards for sound supervision and regulation that are universally applicable. The proportionality approach embedded in their methodology allows assessments to consider the context in which the supervisory practices are applied, commensurate with the risk profile and systemic importance of a broad set of banks, and different stages of development and complexity of financial systems.

The IMF and the World Bank routinely assess compliance of countries with the BCP, normally in the context of the FSAP. The BCP were enhanced in 2012 to incorporate the lessons from the GFC. Assessments of the BCP have revealed progress over the years, but significant and substantial weaknesses still remain across the membership. Some common weaknesses that can undermine the effectiveness of the supervisory process include:

\footnotetext{
${ }^{3}$ See https://www.imf.org/en/About/Factsheets/Sheets/2016/08/01/16/14/Financial-Sector-Assessment-Program for a description of the FSAP program.
} 
- Inappropriate institutional setting. Mandates without sufficient weight to financial stability as well as lack of operational independence and legal protection for supervisors can inhibit timely supervisory actions. ${ }^{4}$

- $\quad$ Lack of skilled resources. The foundation of supervision is sound supervisory judgment. Supervisors need to understand and be able to rigorously challenge industry practices to ensure robust risk management and effective implementation of regulations. This difficult task requires strong technical skills and experience in dealing with financial institutions.

- Insufficient forward-looking analysis. Many supervisors struggle to make risk-based forward-looking assessments of banks and take early action to address weaknesses on a timely basis (i.e., before minimum regulatory requirements are breached).

- Lax credit risk standards. Standards for credit risk management are often weak. Supervisors can enhance their scrutiny of credit underwriting policy, procedures, and criteria, especially with regard to the approval of (new, renewed, or restructured) loans and their financial analysis. Further, many countries would benefit from a more proactive supervisory role in assessing loan classification and valuation of collateral to underscore prudent provisioning practices. Supervisory authorities need to develop the capacity to challenge bank management valuation of loans and should provide banks with conservative guidance on loan classification and provisioning.

- Inappropriate liquidity risk standards and monitoring. Some supervisors do not gather enough information to have a clear view of the liquidity risk incurred by banks. In addition, some do not enforce sufficiently sound liquidity risk management, and many banks do not manage their liquidity needs factoring in scenarios of market wide strain or severe liquidity disruptions.

- Weak corporate governance. Chief Risk Officers are often not senior enough and do not have the appropriate incentives to flag risks to the Board. Banks' Board of Directors need to play an active role in the risk management framework. They should be held accountable for the effectiveness and independence of the risk management function within banks. This is key to create the preconditions for sound business practices and reliable supervisory data (BCBS, 2015c). ${ }^{5}$

- Weak enforcement. Supervision needs to be conclusive. Supervisors must follow through persistently on matters that are identified as these issues progress through the supervisory process. Actual implementation of the regulatory framework and adequate enforcement are key to supervisory credibility.

\footnotetext{
${ }^{4}$ See IMF blog by Tobias Adrian and Aditya Narain “Let Supervisors Do Their Job," February 2019 https://blogs.imf.org/2019/02/13/let-bank-supervisors-do-their-jobs/.

${ }^{5}$ In July 2015, the BCBS revised a set of corporate governance principles that emphasize the critical importance of effective corporate governance for the safe and sound functioning of banks.
} 


\section{Box 1. A Bird's Eye View of the Regulatory Reforms}

The tremendous costs of the GFC on the global economy led the international community to embark in an unprecedented program of regulatory reforms to increase the resilience of the global financial system. The major reforms are usually categorized into four building blocks:

- Building resilient financial institutions. Prior to the crisis, deficiencies in regulation and supervision standards allowed institutions to be weakly capitalized, poorly protected against liquidity shocks and to focus on short term profits without much consideration for long-term business sustainability. Major initiatives to address these issues included new capital and liquidity requirements (BCBS, 2011a and 2017b) and guidelines on compensation practices to reduce bank managers and staff focus on short-term performance at the expense of long run risks (FSB, 2009).

- Ending too-big-to-fail. Due to fragilities in capital ratios and lack of effective resolution frameworks, systemically important banks were bailed-out to keep key financial services available and avoid an even greater impact on the real economy. As a result, a new framework for systemically important institutions was agreed, comprising higher loss absorbance requirements (BCBS, 2013c), the introduction of new resolution frameworks (FSB , 2014) to make these institutions resolvable without meaningful market disruption and taxpayer support, and additional and more intensive supervision requirements (FSB, 2010).

- Making derivatives markets safer. Prior to the GFC, derivatives were mostly traded and cleared bilaterally, creating an opaque market that increased systemic risk due to interconnectedness. New standards require the reporting of over-the-counter contracts to trade repositories and clearing of standardized contracts through central counterparties (BCBS 2015d; FSB, 2017b).

- Transforming shadow banking into resilient market-based finance. Nonbank and non-insurance institutions were mostly left outside of the prudential regulatory perimeter based on the assumption that they would not represent a risk for financial stability. New standards strengthened the oversight and regulation of the shadow banking system (FSB, 2013; and FSB, 2017a).

- These major reforms were complemented by other policy changes to help strengthen the financial system. These policies include guidance on central counterparty resolution (FSB, 2017d); enhanced disclosure requirements (BCBS, 2017c); revised capital treatment of securitizations (BCBS, 2018b); guidelines for the prudential treatment of problem assets (BCBS, 2017d); principles for sound corporate governance (BCBS, 2015c); and guidelines for effective risk data aggregation and reporting (BCBS, 2013).

- The post-crisis regulatory reform substantially strengthened the financial system. The quantity and quality of bank regulatory capital has improved significantly from pre-crisis levels and new liquidity requirements have better equipped banks to withstand liquidity shocks. The reforms have also set proportionately higher regulatory standards, supervisory expectations, and resolution approaches for systemically important financial institutions, potentially reducing the likelihood of the materialization of systemic risks and enhancing the ability to deal with them if they do materialize. While some key aspects remain ongoing work, progress can also be seen in policy areas such as crisis management, shadow banking, financial markets infrastructure, and derivatives (FSB, 2017c).

Addressing weaknesses in the implementation of the BCP are the best approach for DEs to improve supervisory standards. Internal and external assessments of compliance with the BCP are very useful exercises that help create a road map to sounder supervisory practices. For example, the BCP on capital requirements is among the principles with the highest rate of compliance, suggesting that priority should now be given to improving compliance with other principles in order to enhance the resilience of the financial sector. In addition, some enhancements to global standards aim to address weaknesses associated with products and market practices that are not often relevant in DEs. Securitization products and complex derivatives, for instance, tend to substantially increase the complexity of prudential standards, 
but are often not currently material in DEs. The implementation and enforcement of standards dealing with such issues might divert scarce supervisory resources from more pressing priorities.

Supervisors should also identify and address weaknesses in the resolution framework. Even with strong regulation and supervision, banks fail. To mitigate the risk associated with crises and the risk that taxpayers will need to foot the bill, a sound resolution framework, along the lines of the FSB's Key Attributes for Effective Resolution Regimes, is critical. Most DEs have been improving their resolution frameworks, but fragilities are still evident. In many countries, the mandate for resolution is unclear and coordination mechanisms among agencies and authorities are ineffective. A lack of independence and inadequate legal protection for supervisors create risks of decisions being delayed or avoided. Resolution powers are often insufficient and recovery and resolution plans, with appropriate cross-border coordination where needed, are available in only a few places. Supervisors and national authorities should find a satisfactory approach to how they would handle the failure of their largest financial institution.

\section{A. Effective Implementation of the International Standards}

A BCP assessment can reveal specific points of the capital and liquidity framework that need improvement. While $\mathrm{BCP}$ assessments include a thorough evaluation of the adequacy of the capital and liquidity framework, the BCP do not require every country to comply with Basel III in full since they take a proportional approach recognizing the specific characteristics of banks and financial systems in each country. Internationally active banks in BCBS member countries are expected to be subject to the Basel III standards, but such expectation does not apply to smaller banks operating in less complex financial environments. The BCP assessment considers all the different elements of a sound supervisory frameworks and flags potential weaknesses.

The effective implementation of the international standards in DEs is likely to require some adaptations to local circumstances and can usually be enhanced by considering the following: ${ }^{6}$

- Implementing the standards needs to be accompanied with the development of supervisory capacity. The core element of effective banking supervision is sound supervisory judgement to enforce regulation and challenge banks' practices.

- $\quad$ Taking a conservative approach, adjusting international capital and liquidity standards to reflect key differences with financial systems in advanced economies. Adjustments should reflect international minimum thresholds and actual risks of the local financial system.

- Drawing closely on the international standards when framing national regulations, following them in spirit to ensure resilience, increase international comparability, and minimize revisions as financial markets evolve and mature. Departures from international standards should be considered only when there are clear reasons and benefits.

\footnotetext{
${ }^{6}$ See Appendix 1 for an indicative roadmap for the implementation of prudential standards.
} 
- $\quad$ Facilitating industry engagement to ensure consistency of understanding and realistic implementation plans.

- $\quad$ Undertaking quantitative impact studies (QIS) to help inform calibration and policy issues. These should be conducted at an early stage and repeated throughout the policy development and implementation phases. Such studies also enable banks and supervisors to gain familiarity with the new and revised regulations before they are formally in place.

- Implementing transitional arrangements in a manner consistent with operational challenges and banks' abilities to meet prudential ratios without causing substantial disruptions to the banking system. If the impact is meaningful, an appropriate phase-in period that gradually increases the requirement over several years could be established.

- $\quad$ Considering establishing different regulatory tiers to ensure the tailoring of the regulatory framework to the size and complexity of banks (Box 3).

\section{Box 2. The Importance of International Standards}

By establishing minimum prudential requirements, international standards play a key role in promoting stability and efficiency of global financial markets. Disregard to international standards may start a race to the bottom. In a competitive environment, jurisdictions may opt to underbid each other in lowering prudential requirements, hoping to become more attractive to foreign financial firms. This process can become acute in modern financial markets if individual authorities do not adequately consider spillovers and contagion effects that negatively impact other countries. A fragmented global regulatory framework might hinder the trust in the global financial system and the ability of countries to rely on each other's systems. This would create inefficiencies by fragmenting pools of capital and liquidity and impacting cross-border flows. The net result would be inefficient financing and higher risks to national economies. This rationale underpins the multilateral approach to financial regulation and the creation of international standards setting bodies such as the BCBS and the FSB.

Significant deviations from international standards by member jurisdictions would undermine the global standardsetting process. Standard-setter bodies such as the BCBS and FSB develop and agree upon certain standards but have no legal enforcement power. They rely on the commitment of their members to implement what has been agreed as well as on peer pressure mechanisms that encourage jurisdictions to comply with the agreed framework within an established time period. For instance, the BCBS has in place an implementation program called the Regulatory Consistency Assessment Program (RCAP), which is based on peer reviews and disclosure. Full, timely, and consistent implementation by member countries is key to support the international recognition of the standards. Standard-setters' member jurisdictions should therefore lead by example.

At the same time, international standards allow room for adaptations and tailoring, that can be used to establish a proportional regulatory regime. Many international standards, such as the $\mathrm{BCP}$, are expressed as principles or high-level elements that allow jurisdictions to define implementation details according to their specific characteristics. More prescriptive standards can also contain national discretions that are useful to address meaningful differences across jurisdictions. Basel III, for instance, contains provisions that allow jurisdictions to accommodate different practices in relation to external credit rating agencies and different options to treat exposures to public sector entities, banks, and commercial real estate. Moreover, international standards are minimum requirements and national regulators can establish additional or complementary measures that go beyond the agreed minimum. Also, standards such as Basel III are designed for large internationally active banks and regulators can establish different regimes for other banks, when appropriate. Finally, transitional arrangements are national discretions and member jurisdictions can implement standards when they wish but not later than the agreed deadlines. Non-member jurisdictions may consider to implement standards later than these deadlines.

\section{Capital Requirements}

The low quality and low quantity of capital observed in advanced economies (AE) prior to the GFC was not so pronounced in most DEs. Based on lessons learned from emerging markets financial crises in the late "1990s", several DEs had tightened their regulation beyond the requirements prescribed by pre-GFC international standards. Specific circumstances also 
contributed to levels of capital that were generally relatively more robust than banks in AEs. Banks in DEs, for instance, may have limited access to innovative hybrid instruments, which leads to a heavier reliance on common equity and improves the quality of regulatory capital. Additionally, most banks in DEs do not use complex internal models approaches that may have contributed to a less stringent capital framework in AEs. ${ }^{7}$

That said, most DEs have room to improve their capital framework. Most DEs operate under Basel I or a partial version of Basel II. There are gains from improving the quality of capital, risk coverage, risk sensitivity, and the system-wide or macroprudential dimension of the regulatory framework (Figure 1). This section discusses how international standards can be adapted and implemented in DEs to build a sounder regulatory capital framework. Given the modular nature of the Basel framework, which allows some flexibility in implementation, jurisdictions can consider prioritizing the different elements taking into account their expected benefits and implementation challenges.

\section{A. Definition of Capital}

The reforms substantially increased the capacity of banks to absorb losses by increasing the quality of regulatory capital. These improvements came mainly from: (i) greater focus on common equity, (ii) more comprehensive set of regulatory adjustments and deductions from capital, and (iii) stronger requirements for hybrid and debt instruments to be considered eligible for Tier 1 and Tier 2 capital (BCBS, 2011a). These are important advances that should be considered in all countries.

The implementation of the new definition of capital could improve the quality of capital in the future without imposing material costs in DEs. Most DEs rely more heavily than AEs do on common equity, and regulatory deductions are usually not meaningful, reducing the impact of adjusting the framework to the new Basel III definition. But there are exceptions. Banks in some DEs, for instance, hold substantial levels of deferred tax assets or investments in insurance entities. In addition, some DEs' capital frameworks do not deduct good will and intangibles, potentially overstating banks' capital ratios in comparison to the new definition of capital agreed by the Basel Committee.

Implementing the Basel III definition of capital should be a priority in all countries. A strong definition of capital is the cornerstone of an effective prudential framework. Even though the new definition may not affect DEs' banks capitalization in the short run in most cases, it nonetheless ensures that regulatory capital will continue to absorb losses in the future, as banks might change their profile. The absence of an immediate impact substantially facilitates implementation and should be used to the regulators' advantage. If there is a meaningful impact, this is a sign that the quality of capital is low, and that capital may be unable to absorb losses as expected. In these cases, despite implementation challenges, the objective is even more important.

\footnotetext{
${ }^{7}$ See Box 4 for a discussion about internal models approaches in DEs.
} 


\section{Figure 1. Adoption of Banking Standards among Non-Basel Committee Members}

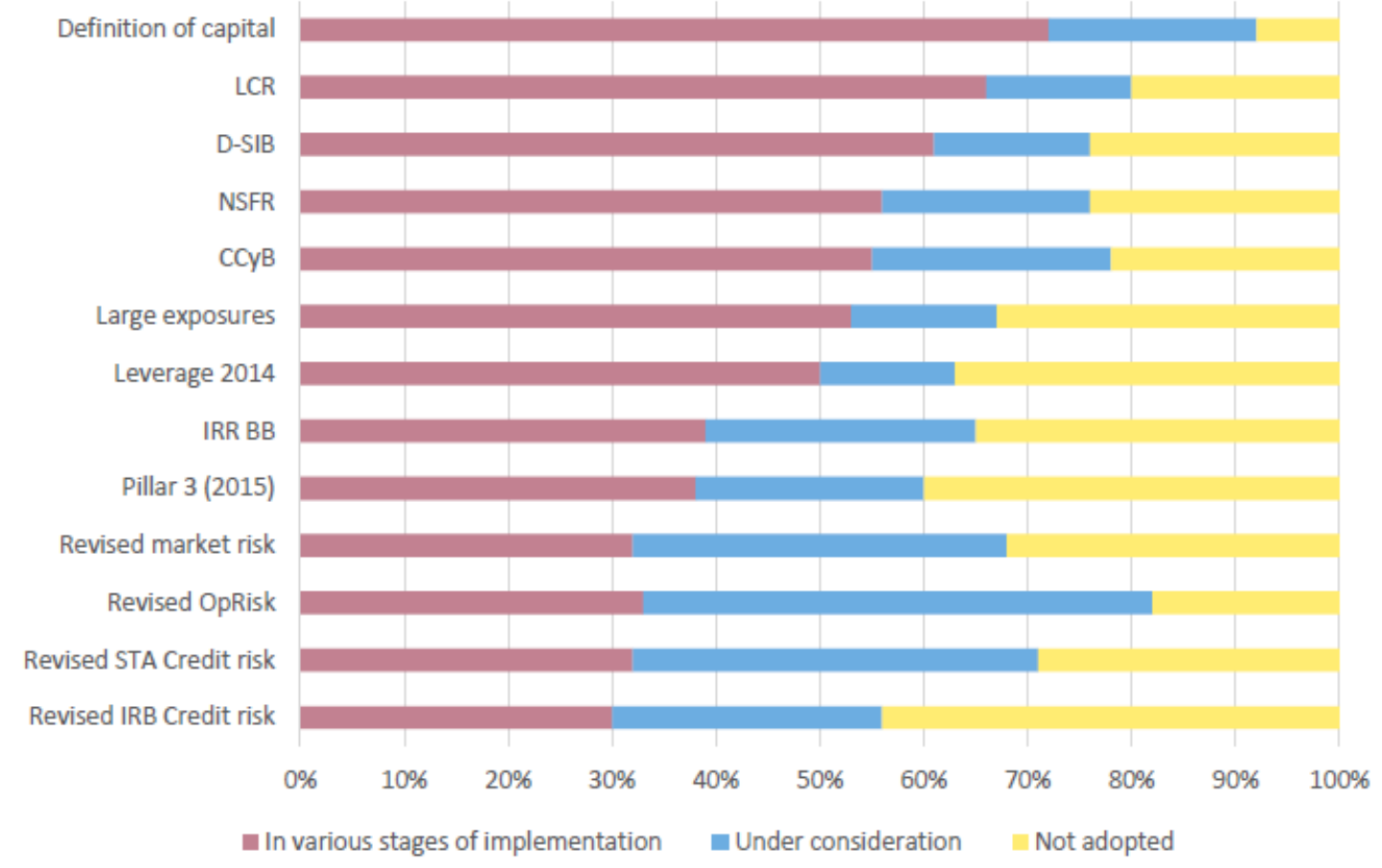

Source: Hohl, S., M.C. Sison, T. Stastny, and R. Zamil, 2018, "The Basel Framework in 100 jurisdictions: implementation status and proportionality practices," FSI Insights on policy implementation No. 11, November (Basel: Bank for International Settlements).

DEs can implement the Basel III definition of capital in a simpler but still robust way. Some regulatory adjustments and waivers for deductions have complex rules that reflect the specific circumstances of the international standard-setting process relating to particular AEs and typically do not apply to DEs. DEs could consider, for instance, fully deducting: (i) mortgage servicing rights; (ii) deferred tax assets from time differences; and (iii) significant investments in unconsolidated financial institutions. This would create a simpler framework, typically without a substantial impact.

The negative impact of deducting hybrid and debt instruments, which were eligible for capital under Basel I/II and will no longer be accepted, could be mitigated through transitional arrangements. The implementation of the Basel III definition of capital is likely to make previously issued hybrid and debt instruments ineligible for regulatory capital. These instruments usually have long maturities and are more expensive than senior debt funding. Authorities need to consider their volume in the banking system, as well as their maturity and the possibilities of redemption when designing the transition. One way to support the transition would be to encourage or request the industry, when issuing those instruments, to include a regulatory event clause before the conclusion of the regulatory changes. Considering that the new debt instruments are likely to be more expensive than those allowed under Basel I/Basel II, authorities should avoid creating incentives for banks to front load issuances of instruments that will no longer be eligible under Basel III rules. Such incentives could be mitigated to some extent by 
restricting grandfathering only to instruments issued before the announcement (not before the implementation) of the new regulation.

\section{B. Minimum Requirements and Capital Buffers}

Basel III changed the structure of the capital framework by creating three independent minimum capital ratios and supplementing them with buffers that can be drawn down in periods of stress (Figure 2). Banks are required to meet different ratios of common equity, Tier 1, and total capital. The three established minimum ratios should be observed at all times. In addition, aiming to reduce the cyclicality of regulation and to encourage the buildup of capital though the retention of earnings, banks are expected to build up higher capital in good times, which can be drawn down when losses arise (capital buffers).

The implementation of the new capital structure is important for DEs. The implementation of the new structure is not complex and supports the greater emphasis on common equity. ${ }^{8}$ Having the definition of the three independent ratios established in regulation is also important for disclosure and market discipline, as common equity and Tier 1 capital ratios are now common benchmarks to assess capitalization of banks.

\section{Capital Conservation Buffer}

The creation of capital buffers in addition to minimum requirements enhances the macroprudential dimension of regulation and facilitates gradual supervisory action. The capital buffer established by Basel III is formed by three elements: the capital conservation buffer, the countercyclical capital buffer, and the systemically important banks buffer. In practice, these three elements complement each other and form a single capital buffer.

The capital conservation buffer suits the needs of DEs. The requirement is based on a simple capital conservation rule that is uniformly applicable to all banks and is not expected to change over time. When buffers are drawn down, the rule limits dividends distributions, share-backs and staff bonus payments and thus facilitates the preservation of capital. The simplicity of the rule can help many countries that are challenged in limiting the distribution of earnings and taking remedial actions before breaches of the minimum regulatory thresholds occur. In this context, the separation of minimum requirements and capital buffers and the gradual automatic restrictions embedded in the framework are particularly useful.

\footnotetext{
${ }^{8}$ The new structure would encompass separating minimum requirements and capital buffers and establishing three independent minimum capital ratios (common equity, Tier 1, and total capital).
} 


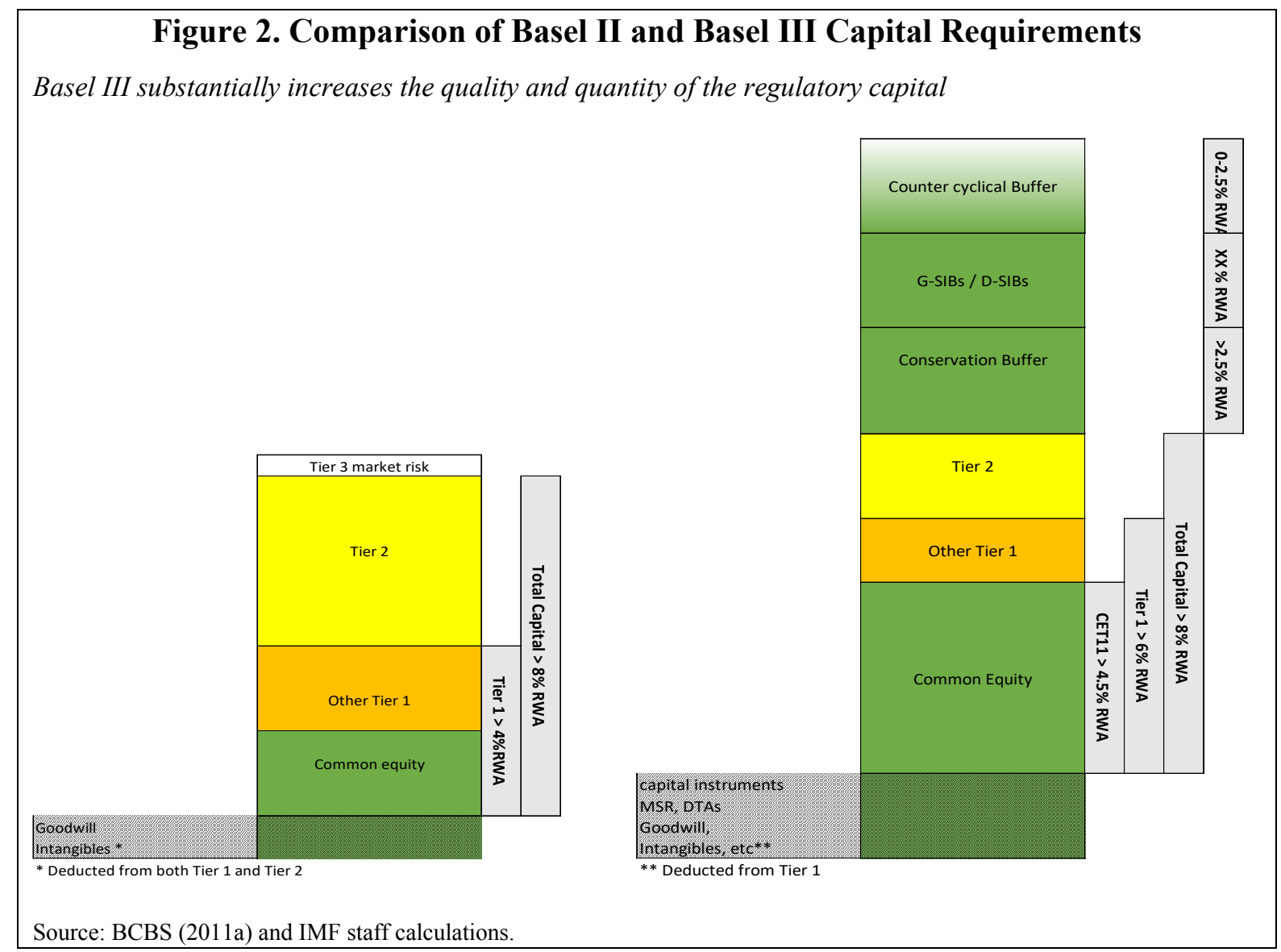

DEs should exercise caution to not automatically recalibrate the thresholds prescribed by Basel III, because they have typically already established minimum capital requirements that are substantially higher than those prescribed by Basel II. The additional capital served them well during the GFC and is usually necessary due to higher economic and financial volatility and weaker institutional settings, which lead to higher risks than in the AEs. The authorities should carefully consider the appropriate target level of capital, including all capital buffers, to ensure appropriate capitalization without hindering the proper function of the banking system.

\section{Countercyclical Capital Buffer}

The countercyclical capital buffer is designed to protect the financial system from periods of excessive credit growth that have often been associated with the build-up of systemic risks (BCBS, 2010). The aim is to ensure that the banking sector, in aggregate, has enough capital to maintain the flow of credit after a systemic shock. The buffer may also help to lean against the build-up phase of the cycle. The tool requires national authorities to monitor the build-up of systemic risk and apply judgement to determine the appropriate level for the capital buffer. 


\section{Box 3. Proportionality in the Regulation of Small Banks}

Compliance costs associated with prudential regulation can be substantial for small banks. The post-crisis regulatory reform completed the prudential regulatory framework, closing gaps identified after the GFC. However, it increased its complexity, particularly in risk areas where many small banks have little or no business. As a result, small banks might not have the necessary scale or business model that warrants the full implementation of the new standards. ${ }^{1}$

It might be appropriate to differentiate regulation and establish simpler, but not less conservative, requirements for small banks. The failure of a small institution can have significant impact on the reputation of supervisors. Small institutions are also prone to contagion and their collective failure may have financial stability implications. Therefore, while it might be advisable to adjust the regulation developing simpler standards, the prudential framework should not jeopardize financial stability.

Size is not the only variable that should be considered when identifying banks eligible for simpler standards. While the size of a bank is an important dimension, the risk profile and business model are also important factors. Small banks that rely on sophisticated products and complex business models should be subject to a regulatory framework that is able to capture their risks.

An alternative could be to use existing financial statements and reports to impose capital requirements. The regulatory framework should, to the extent possible, aim to maintain risk sensitivity while avoiding the creation of additional supervisory reports and processes for its implementation. In this sense, an alternative is to calculate riskweighted assets by using risk weights that apply to exposures already calculated and segregated for other purposes (e.g., accounting or other existing supervisory reports). This approach can be easily implemented, does not require the development of costly new information systems, and is more risk sensitive than simple LRs.

The benefits of some key reforms nonetheless outstrip the additional compliance costs of some regulations for smaller banks. Liquidity and concentration risks tend to be higher in small banks. While some reporting burden may be alleviated, new reports may still be needed to ensure timely supervisory assessment.

Strong corporate governance is essential regardless of the size of the bank. Many episodes of small bank failures are driven by corporate governance issues. Supervisors should enforce standards consistent with international best practices. $^{2}$

Strong resolution frameworks and effective financial safety nets are important when considering proportional regulation for smaller banks. These would ensure that the resolution of smaller banks can be effected in an orderly manner without endangering financial stability.

${ }^{1}$ See Carvalho et al. (2017) and Hohl et al. (2018) for discussions about proportionality approaches implemented by different jurisdictions.

${ }^{2}$ See BCBS (2015b).

Lack of data and an underdeveloped institutional setting can constrain the operation of the countercyclical capital buffer in DEs. The countercyclical buffer is subject to a range of biases towards inaction. Inaction is often exacerbated by political pressures and lobbying from the financial industry that focus excessively on short-term costs and disregard long-term benefits, such as financial stability. Independent institutions and a strong accountability framework that could counterbalance these pressures are not always present. In such cases, a stronger role for rules (rather than judgement) in the decision framework to activate the buffer may be advisable. 
The assessment of systemic vulnerabilities and, therefore, the use of the buffer can also be hampered by the lack of sufficiently long economic and financial data series. DEs should invest in improving the quality of data collection to ensure appropriate policy making (IMF, 2014a, $2014 b, 2014 c)$.

\section{Domestic Systemically Important Banks (D-SIBs)}

The impact that the distress or failure of a systemically important bank (SIBs) can have on the real economy motivated the adoption of higher loss absorbency requirements. ${ }^{9}$ Some large, interconnected banks can have a disproportional impact in the domestic financial system when compared to non-systemic institutions. To mitigate the negative externalities posed by D-SIBs and the moral hazard costs associated with implicit government guarantees, the Basel Committee developed a set of principles to guide jurisdictions in the identification of these institutions and to establish higher loss absorbance standards for them (BCBS, 2012b).

The D-SIBs framework has broad rationale and applicability and addresses the needs and characteristics of DEs. The principles are flexible and allow regulators to impose additional requirements based on the specific features of the country and its domestic banking sector. The challenge for DEs is to make the high-level recommendations operational.

To apply the framework, DEs may not benefit from developing complex scoring functions to identify D-SIBs and allocate them into buckets. SIBs are often easier to identify in a national context. Supervisors and market participants usually have a clear view about which are the D-SIBs operating in their markets. The challenge is to develop a procedure to formally identify and nominate the institutions as D-SIBs to avoid the perception that the nomination is arbitrary. In this regard, scores generated by mathematical formulas that weight different indicators of systemic importance can be helpful. Nevertheless, it is important not to be misled by the precision suggested by these approaches. It is key to ensure that the result is intuitive and that it treats similar institutions equally. It might also not be necessary to include many indicators in the scoring formula. Traditional indicators such as size, interconnectedness, lack of substitutes, and complexity are usually highly correlated in DEs. If all the indicators are pointing to the same institutions, a parsimonious approach helps to keep the regulatory framework simple and intuitive.

The calibration of the higher loss absorbency requirements for D-SIBs involves supervisory judgment. Quantitative analyses that estimate the impact of a D-SIB failure on the domestic economy are useful exercises to consider in the calibration. Usually, several approaches are taken into account to calibrate the D-SIB buffer, including historical losses in the country's banking sector and stress test results. Another common methodology is the equal expected impact approach. This approach calculates the buffer required to bring down the probability of default of a D-SIB to the level that reduces the economic cost of failure of the bank to that of a

\footnotetext{
${ }^{9}$ The approach for D-SIBs draws on the approach taken for globally systemic banks (G-SIBs) developed by the BCBS and the FSB. See BCBS (2012b) "A Framework for dealing with domestically systemically important banks" https://www.bis.org/publ/bcbs233.htm.
} 
reference bank that is not a D-SIB. However, these analyses have limitations that need to be considered by the authorities. The final decision needs to include, among other criteria, the degree of systemic importance of the banks and the soundness of the resolution framework.

Supervisors should be aware that the D-SIB exercise risks creating a perception that these institutions that might be considered too-big-to-fail. Moral hazard costs associated with expectations of implicit government support may amplify risk-taking, reduce market discipline and create competitive distortions. While possible restrictions on distributions created by the capital buffer may not allow to keep the identification of D-SIBs confidential, communication efforts should stress that the goal is to reduce the impact and negative externalities of eventual failures and that institutions are not considered too-big-to fail.

The D-SIB framework should also include stronger supervision and resolution requirements. D-SIBs should be subject to more intense supervision that includes more frequent inspections and interactions with senior management and higher supervisory expectations on corporate governance, risk management, and data reporting. Supervisors should also require D-SIBs to prepare recovery and resolution plans that should be thoroughly analyzed and challenged to ensure that they are effective and implementable.

\section{Risk-Weighted Assets}

\section{Standardized Approach for Credit Risk}

The robustness of the standardized approach for credit risk has been strengthened. The Basel Committee revised the minimum standard aiming to reduce automatic reliance on external credit ratings, enhance granularity and risk sensitivity, update calibrations, and provide better clarity on its application (BCBS, 2017b). The new standard also improved the treatment of off-balance sheet exposures and addressed previously unattended risks, such as the ones from exposures with currency mismatch.

The standardized approach for credit risk is the most relevant, and sometimes the only variable driver of the capital charge in DEs. Banks in DEs tend to have limited trading-book operations and, in some cases, have not implemented the operational risk and market risk frameworks. Due to its complexities as well as data requirements and other minimum requirements, the Internal Ratings-Based (IRB) approach has not been considered a viable option in most DEs. The standardized approach is also used by many banks in AEs and will be used as the base of the output floor for IRB banks, making it universally relevant.

DEs should incorporate the new standard focusing on their most relevant credit portfolios. Considering that the revisions finalized by the Basel Committee kept the same structure prescribed by Basel II, there is no need to revamp the whole framework at once. The regulatory treatment for housing mortgages portfolios, for instance, had shortcomings under Basel I and II standardized rules despite their importance in most countries. The new standardized approach achieved substantial progress in making the framework clearer and more risk sensitive and, thus, could be considered by the DEs where such portfolios are significant. Other portfolios, such as 
retail loans had revisions that generated a more granular treatment by distinguishing, for instance, between revolving facilities (where credit is typically drawn upon) and trans-actors (where the facility is used to facilitate transactions rather than a source of credit). However, these distinctions are typically less relevant to DEs.

DEs could go beyond the revisions finalized by the Basel Committee to further increase the risk sensitivity of the capital framework. While reducing mechanistic reliance on external credit ratings, the new standardized approach continues to use such ratings to differentiate loans by their risks. This approach has limited applicability for DEs due to the low share of borrowers that are rated. ${ }^{10}$ On the other hand, some asset classes that tend to be more important in DEs, such as regulatory retail exposures, are subject to a limited granular treatment. DEs may consider the merits of providing greater risk sensitivity by using objective drivers of risk, such as characteristics of the borrowers (e.g., leverage, profitability, size) or the characteristics of certain types of collateral to further differentiate the operations. Although it has proved difficult to select such drivers at a global level, it is usually possible to do so at a country level. For instance, in some DEs, based on historical experience, credit card loans tend to be riskier than auto loans or payroll deduction loans. Efforts to further differentiate risk across credit operations should not result in average lower capital requirements than those implied by the Basel rules. For instance, if a jurisdiction opts to create further different classes of retail exposures, the weighted average risk-weight for the combined retail classes should not be lower than those prescribed by the Basel Committee.

Parameters defining portfolios may need to be adjusted to better fit DEs. The Basel framework prescribes some objective parameters to define portfolios. For instance, the framework defines small- and medium-sized enterprises (SMEs) as "corporate exposures where the reported sales for the consolidated group of which the firm is a part is less than $€ 50$ million." The $€ 50$ million criteria may be too high for many DEs. The limit could be lowered to ensure that the resulting SME portfolio has a minimum granularity and is composed of firms whose risk is actually managed by banks as SME risk. A similar issue arises in the definition of the regulatory retail portfolio.

Countries should carefully consider challenges to implement the option that allows banks to classify corporates as "investment grade." The new standardized approach allows banks that are incorporated in jurisdictions that prohibit the use of external ratings for regulatory purposes to apply a lower risk-weight for corporates that banks classify as "investment grade." The criteria for this classification may be subjective and difficult to enforce. Unless their supervisory systems can ensure compliance with the standards and consistent classification across banks, supervisors are strongly encouraged to carefully assess the risks of an inadequate implementation of this option.

\footnotetext{
${ }^{10}$ The new framework provides an alternative to the use of external credit ratings for corporates and banks. Nevertheless, implementing these alternatives can be a challenge and their benefits in terms of risk sensitivity is relatively limited.
} 
Improvements to the regulatory treatment of off-balance sheet exposures and treatment of unhedged exposures are pertinent for most DEs and are recommended as an implementation priority. The new standard creates a risk-weight multiplier for certain exposures that embody currency mismatch. The goal is to address the additional credit risk posed by unhedged retail and residential real estate exposures to individuals where the lending currency differs from the currency of the borrower's source of income, such as mortgages denominated in foreign currency. In several countries, these exposures are relevant. In such cases, the increased risk weight would help to mitigate the risks that these exposures pose to financial stability. The new standard also recalibrates the credit conversion factors used to estimate the risk posed by some off-balance sheet exposures. The zero percent credit conversion factor for unconditionally cancellable commitments was increased. This increase is especially relevant for countries where the legal framework, risk management capabilities, and other factors constrain banks' ability to cancel such commitments in practice.

Countries whose banks have significant investments in asset management products would benefit from an update to the regulatory treatment of such exposures. The Basel Committee revised the policy framework for the prudential treatment of banks' investments in the equity of investment funds (BCBS, 2013e). The revised treatment is based on the principle that banks should apply a look-through approach to identify the risks of underlying assets whenever they are investing in funds. The revised standard better accounts for funds' leverage and reflects more appropriately the risk of a fund's underlying investments, substantially improving the regulatory treatment.

\section{Market Risk}

The new framework for market risk substantially upgrades the existing framework by increasing consistency, coherence, and risk capture. It is expected to better capture tail risks and preventing arbitrage across the banking and trading books, while raising the bar for using internal models (BCBS, 2019). It also substantially raises the requirements for market risk capital, thus addressing the material undercapitalization of trading-book exposures prior to the GFC.

The new framework is formed by three different approaches: internal models, standardized, and simplified standardized. The complexity of the internal models and, to some extent, of the standardized approach, makes them relatively challenging to implement. These approaches increased the number of risk factors and enhanced the use of correlations across them, improving risk capture but sacrificing simplicity. The greater reliance on risk sensitivities as input into the capital calculation ultimately makes the new standardized approach reliant on pricing models of banks, complicating its consistent implementation in smaller institutions and in DEs. Aware of these challenges, the BCBS created a simplified standardized approach for use by banks that have small or non-complex trading portfolios.

The relative unimportance and simplicity of the trading book in many DE banks makes the simplified standardized approach the most suitable approach for them. The simplified standardized approach relies on the same structure of the Basel II market risk approach, considerably lowering implementation costs. Most importantly, the framework was recalibrated 
to tackle the lessons from the GFC and to reduce arbitrage opportunities between the trading and the banking books.

In jurisdictions where even, the simplified standardized approach is considered not suitable, a flat surcharge to cover market risks could be an option. In countries where market risks are low and relatively uniform across banks, and the size of banks makes compliance and reporting costs a major concern, it might be appropriate to implement a credible flat surcharge to cover market risks. The surcharge could, for instance, increase capital requirements by a fixed amount in terms of risk-weighted assets (RWAs) or total assets that are kept at fair value. As trading books of banks grow and become more complex, the capital treatment should evolve towards the international standard.

Foreign exchange risk requires an appropriate regulatory treatment. While the relatively small size of trading books in DEs might favor very simple approaches for market risk, this is usually not the case for foreign exchange risk (across trading and banking books). ${ }^{11}$ Given the modular nature of the Basel framework, it is possible to establish a more risk-sensitive approach for foreign exchange and other relevant risk factors, and complement it with simpler options to tackle the remaining risks.

The revised boundary between the trading book and the banking book should be adopted even if the new framework is not fully implemented. Basel I and II define the trading book based on banks' trading intent. In practice, the definition is difficult to enforce and allows ample room for capital arbitrage. The Basel III framework is more prescriptive, providing additional guidance on the appropriate contents of the trading book and reducing the ability of the banks to arbitrage the boundary. The enhanced boundary definition can be adopted independently of the remaining parts of the framework and, therefore, can be a meaningful improvement to the market risk framework for DEs.

Supervisors should also enforce sound valuation practices of instruments accounted for at fair value. Capital requirements can mitigate market risk but are no substitute for strong prudential valuation practices. The GFC revealed substantial weaknesses in the systems and process of banks that led the Basel Committee to enhance the prudent valuation guidance (BCBS, 2009). The guidance is particularly relevant for illiquid positions that can be meaningful in some banks in DEs.

\section{Operational Risk}

The Basel II operational risk capital framework was completely overhauled (BCBS, 2017b). The new standard is expected to address the shortcomings of the previous framework by increasing the consistency and reducing the complexity in RWAs' calculations while better capturing the operational risk incurred by banks. The so-called advanced measurement approach (i.e., the

${ }^{11}$ This might also be the case of commodities risk in some countries. 
internally modelled approach) for calculating operational risk was removed. The new framework consists of a single standardized approach to be used by all banks.

However, the sole adoption of the new Basel III indicator for operational risk may not result in substantial changes for some DEs. The new framework replaces the proxy indicator for operational risk, but the improvement in terms of operational risk capture is relatively limited. Risk sensitivity is expected to increase mainly due to the use of banks' internal operational loss data. Nevertheless, this improvement does not apply to small banks and the methodology requires 10 years of high-quality annual loss data that may be unavailable in some DEs. Finally, the calibration of the framework targets undercapitalization at large banks and should not meaningfully impact small- and medium-sized banks.

Supervisors should prioritize the implementation of operational risk management standards to complement the transition to the new Basel III indicator. The Principles for Sound Operational Risk Management (BCBS, 2011b) represents a comprehensive set of minimum standards to encourage better operational risk management. In moving to the new Basel III indicator, supervisors should require banks to develop operational loss databases regardless of adopting the new framework. Developing internal loss databases is the first step to sound operational risk management. The minimum standards for the use of loss data prescribed in the Basel rules constitute good guidance to ensure sound datasets. Supervisors in DEs might find it useful to enforce the standards proportionally to the size and operational complexity of each bank even if they are not used to calculate the operational risk capital charge.

DEs implementing the proxy indicator for operational risk should pay careful attention to calibration and the variables driving the indicator. The new proxy for operational risk, the Business Indicator, is based on variables such as interest income and expenses, fees and profits. ${ }^{12}$ These variables can usually be drawn from financial statements but, depending on the accounting standard adopted in each country, some of these variables might not be readily available according to the exact definition prescribed by international rules. In such cases, it might be preferable to tweak the indicator and use the available accounting information rather than to require banks to prepare new reports. By using financial statements and existing regulatory reporting, supervisors may be able to design the proxy indicator without requiring additional reporting requirements. As long as the changes do not create a bias towards lowering the indicator, this adjustment might reduce compliance and enforcement costs without material adverse consequences.

\section{Leverage Ratio (LR)}

The regulatory reforms introduced an LR to supplement the risk-based capital requirements (BCBS, 2014a). The LR is designed to constrain the build-up of leverage in the banking sector by reinforcing the capital framework with a non-risk-based measure. The new requirement is expected to mitigate the risk of destabilizing deleveraging processes and introduce additional

\footnotetext{
12 The Basel II proxy, the Gross Income, is also based on similar variables.
} 
safeguards against model risk. In addition, the finalized Basel III reforms introduced an LR buffer to further limit the leverage of G-SIBs (BCBS, 2017).

\section{Box 4. Internal Model Approaches in DEs}

Internal model approaches were expected to encourage sound risk management. Internal model approaches were designed to be more risk sensitive, generating a capital charge that better fits the actual risks incurred by banks. Higher skin-in-the-game when banks take more risk should, in principle, provide regulatory incentives against excessive risk taking. Furthermore, capital incentives embedded in the framework were expected to promote the adoption of stronger risk management practices by the banking industry.

In practice, inconsistency in RWAs' calculations limited the expected benefits. Basel Committee studies have shown that risk weights for credit and market risk vary significantly across banks (BCBS, 2013b; BCBS, 2013d). Hypothetical portfolio exercises, for instance, revealed a notable dispersion in the estimates of risk parameters. As a result, a meaningful part of the risk weights variability is driven by banks' and supervisory practices. This variability has generated concerns about regulatory arbitrage and inconsistent application, highlighting the challenges to enforce sound internal models approaches.

IRB requires strong governance mechanisms, skills, and capacity in the banks. Internal model approaches are complex and require specialized skills sets within banks to apply appropriate modeling techniques used in the estimation of risk parameters. Risk governance is crucial across the three lines of defense to ensure oversight is applied to each phase of model development, deployment, and ongoing validation.

Accepting internal models for regulatory purposes is resource intensive and might distract supervisors from more pressing issues. Owing to the complexity the framework requires supervisors with strong knowledge of econometric and statistical techniques, as well as of capital regulation, corporate governance, and risk management. Supervisors may need to authorize many quantitative models, sometimes hundreds, that require maintenance and monitoring over time. This resource intensive and challenging process might divert highly capable supervisors from broader supervisory assessments and actions that might be more important to help ensure financial stability.

Capital savings provided by internal model approaches may be small (or non-existent) in DEs. One of the drivers of banks' decision to implement internal models is the expectation of a lower capital charge. Nevertheless, this is often not the case in DEs. Higher market volatility and probability of defaults and legal challenges to enforce collateral that reflect in higher loss given default may result in practice in capital requirements above those prescribed in the standardized approaches.

DEs that decide to implement internal models' approaches should address supervisory shortcomings first and develop a long-term plan that includes strong interaction with the banking industry. No country needs to implement internal models approaches to follow the Basel framework and DEs are not expected to do so. However, if DEs decide to allow banks to use internal models for regulatory capital purposes expecting to improve financial stability and foster better risk measurement and management practices, a road map should be developed to allow supervisors and the banking industry to build the necessary capacity. These plans should be sufficiently long (several years) and emphasize communication between supervisors and the industry along the whole process.

Typically, the LR is not a relevant binding constraint in DEs. The GFC revealed that banks could build-up excessive on- and off-balance sheet leverage while still showing relatively strong risk-based capital ratios. One of the main reasons for this discrepancy was the use of internal models approaches that reduced risk weights and increased model risk. Another important reason came from derivatives and other off-balance sheet exposures that were not appropriately 
captured by the risk-based framework. As banks in DEs do not use internal models extensively for regulatory capital and usually have limited derivatives exposures, implementation of the LR tends to have relatively limited practical impact, particularly when its calibration is maintained along the ratios recommended by the Basel standards.

In some circumstances the LR may be helpful in DEs to limit excessive exposures of banks to sovereigns and other low RWAs. Standardized risk weights may underestimate actual risk and correlations, and the LR can thus potentially be useful to restrict excessive exposures to low RWAs, such as exposures to domestic sovereigns which are usually exempted from the risk-based capital charge and concentration limits. However, the implementation of the LR does not preclude other supervisory and regulatory measures that could be more effective dealing with these risks. ${ }^{13}$

Implementing the LR can be relatively complex. The LR is meant to be a simple and transparent measure of banks' leverage. However, the simplicity of the standard is constrained by the need to establish a global measure that is not biased by differences in accounting practices. Calculation of derivatives exposures, in particular, can be relatively burdensome. DEs that do not have meaningful derivatives exposures should consider simplifying the calculation of total exposures. A possible simplified treatment could, for instance, consider the amounts of derivative exposures already calculated for credit risk purposes.

DEs that opt to implement the LR might need to adjust its calibration to ensure it works as an effective backstop. The proposed 3 percent calibration might be too low for the LR to work as an effective backstop in DEs that have implemented risk-based capital requirements that are higher than international standards. In these circumstances the calibration of the LR should be increased. However, to avoid incentives for excessive risk taking, the revised calibration should ensure that the LR works as a backstop to the risk-based framework. It should not be the binding capital requirement for most banks during the non-boom phase of the financial cycle (Fender and Lewrick, 2015). The 35 percent conversion ratio between the Tier 1 risk-based capital requirements and the LR embedded in the Basel standards is a good reference for appropriate calibration. ${ }^{14}$

\section{E. The Second and Third Pillars}

Pillars 2 and 3 are key components of the Basel capital framework. A robust implementation of Pillar 2, including banks' assessment of their capital adequacy and supervisors review of such assessment, is critical to ensure that risks not appropriately covered under the Pillar 1 are taken

\footnotetext{
${ }^{13}$ See Dell'Arricia et al. (2018) "Managing the sovereign bank nexus," https://www.imf.org/en/Publications/Departmental-Papers-Policy-Papers/Issues/2018/09/14/Managing-theSovereign-Bank-Nexus-45133.

${ }^{14}$ The "conversion" should include minimum requirements and the capital conservation buffer. For instance, assuming an 8 percent minimum Tier 1 requirement and a 2.5 percent capital conservation buffer, the LR could be set at 3.5 percent. Eventual surcharges for D-SIBs could follow the Basel approach for globally SIBs, and create a leverage buffer that equals 50 percent of the risk-based surcharge (BCBS, 2017).
} 
into account. Pillar 2 also fosters improvements to banks' risk management and monitoring and requires banks' Boards to take responsibility for their institutions' capital policies. Finally, the disclosures provided under Pillar 3 are essential in ensuring market discipline as a complement to the other two pillars.

A sound Pillar 2 implementation is a challenging long-term project but should be a priority for DEs. Pillar 2 is based on high-level principles that require banks and supervisors to comprehensively assess the risks taken by banks and take corrective or risk mitigating actions when needed. These activities are at the core of the banking supervision function. Implementing the Pillar 2 framework usually takes time due to the need to further enhance supervisory capacity and industry practices but can substantially strengthen supervisory practices and banks' risk management and corporate governance.

Pillar 2 implementation should be comprehensive and ensure that supervisors have the range of powers needed to take timely corrective actions. Supervisors should have the ability to require more capital or liquidity and limit the distribution of dividends based on their assessment of banks' risks. However, increased capital should not be the only option. Other measures - such as strengthening the level of provisions and reserves, imposing limits on specific exposures, and improving internal controls and risk management - must also be available and implemented as needed. Failures to comply with the Basel Core Principle 11 on corrective and sanctioning powers of supervisors are frequently observed in IMF/World Bank FSAP assessments and should be addressed promptly.

Pillar 2 tools and processes should be fully integrated into the supervisory approach. Pillar 2 assessments need to be risk based, forward looking, and generate a comprehensive view of banks' risks and capital adequacy. As such, they are an integrated piece and a key component of the supervisory approach. In particular, the risk-based supervision framework, supervisory risk assessment ratings (such as CAMELS), supervisory stress testing, and the internal capital adequacy assessment process (ICAAP) are integral parts of the supervisory review process and should feed into each other seamlessly. In countries where these tools have been developed independently, there should be an effort to review and integrate the overall supervisory process.

Initial implementation of ICAAP could focus on large banks. Experience shows that the initial stages of the Pillar 2 implementation are critical. To be effective, the ICAAP should form an integral part of the management process and decision-making culture of the bank. It is a learning process for banks and supervisors that usually takes several years and requires intense interaction between the involved parties. In that regard, it might be useful at the initial stages to follow a risk-based approach and therefore establish Pillar 2 requirements only for large banks. This would allow supervisors to gain experience before expanding the requirements to the rest of the banking system. For instance, smaller banks could be exempted from formal ICAAP submissions in the first three years, or an exemption could be established for more complex requirements (e.g., stress testing). 
Pillar 3 disclosure requirements might warrant adjustments to avoid excessive compliance costs in DEs. Pillar 3 requirements were substantially revised to enable market participants to better compare banks' disclosures (BCBS, 2015a; BCBS, 2017a). The most significant revision introduced templates for quantitative disclosures with precise definitions and a fixed format. While the new templates are a key step forward, their detailed nature and close relationship with international capital standards might make them less relevant and costlier to implement by smaller local banks. Supervisors in DEs should consider simplifying these templates, possibly reducing the granularity of the information required and disregarding templates that cover standards not implemented in their country. Nevertheless, the definitions used in the Basel framework should be maintained to the extent possible to allow comparison with international peers.

\section{F. Interest Rate Risk in the Banking Book (IRRBB)}

Interest rate risk in the banking book (IRRBB) refers to the current or prospective risk to the bank's capital and earnings arising from adverse movements in interest rates, which affect the institution's banking book positions. Changes in interest rates can affect a bank's earnings by altering interest-sensitive income and expenses, affecting net interest income. This risk is inherent to the banking business and its successful management can have an important impact on profitability and shareholder value. However, excessive interest rate risk can pose a significant threat to a bank's current capital base and/or future earnings if not managed appropriately.

The Basel Committee has issued standards strengthening the framework for IRRBB (BCBS, 2016). Although the international community has not agreed on a Pillar 1 charge given the heterogeneous nature of the risk, the Basel Committee has enhanced supervisory expectations and disclosure requirements for a bank's IRRBB management process. The standardized framework was also updated and constitutes a useful option for DEs to consider when establishing their capital charge.

IRRBB is often more important to DEs than trading-book risks, as trading books may be small. Given the relevance of this risk, countries should consider imposing an interest rate risk capital charge even if their Pillar 2 framework is still being developed.

Supervisors have discretion to apply either a Pillar 1 or Pillar 2 approach. The Pillar 2 approach tends to be more flexible and, therefore, is better positioned to accommodate complex banks' business models and the wide heterogeneity across banks. However, it is difficult to implement and enforce, requiring high-quality bank risk management, sound supervisory review processes, and strong capacity of supervisors to exercise judgement. A more standardized risk charge, applied under Pillar 1, can be preferable when banks exposures to IRRBB arising from complex financial product are not substantial or when banks risk management and supervisory capacity are still developing. 


\section{LIQUIDITY REQUIREMENTS}

The GFC demonstrated the importance of a strong liquidity base to support financial stability and the proper functioning of the banking system. There is a positive correlation between solvency and liquidity and, while strong capital requirements are necessary for financial stability, there is no substitute for a liquidity base and strong liquidity risk management. Liquidity shocks impair the provision of credit (Strahan, 2012) and can lead to the failure of solvent banks. However, before the GFC, there was no international quantitative standard and guidance on liquidity risk management was weak. This gap was filled by the Basel Committee's "Principles for Sound Liquidity Risk Management and Supervision" (BCBS, 2008) and two minimum requirements aiming to enhance the resilience of banks to liquidity risk.

Basel III introduced a comprehensive framework for liquidity. The Basel III reforms include a set of prudential ratios and risk management standards that represent a comprehensive regime for liquidity regulation. The two ratios are designed to promote short-term resilience to liquidity shocks (Liquidity Coverage Ratio) and encourage a stable funding profile in the long-term (Net Stable Funding Ratio). The risk management standards are designed to set out the minimum expectations for the management and supervision of liquidity risk.

\section{A. Liquidity Coverage Ratio (LCR)}

The LCR aims to improve the short-term resilience of banks' liquidity profile. The LCR framework aims to ensure that banks have an adequate stock of unencumbered high-quality liquid assets (HQLA) that can be converted into cash at little or no loss of value in private markets to meet liquidity needs in a stress scenario (BCBS, 2013a). ${ }^{15} \mathrm{It}$ is calculated as the ratio of HQLA divided by total net cash outflows for the scenario ${ }^{16}$ for 30 calendar days into the future. The standard requires that, absent a situation of financial stress, the value of the ratio be no less than 100 percent.

The LCR has several benefits compared with traditional metrics used to calculate bank liquidity. The LCR builds on traditional "coverage ratio" methodologies as a measure of banks' exposure to contingent liquidity events. ${ }^{17}$ While conceptually equivalent to traditional coverage ratios, the LCR has several benefits, including: (i) it is calibrated against stressed assumptions of assets and liabilities; (ii) it introduces rigorous eligibility criteria for HQLA where assets need to meet clear definitions and continually meet market liquidity characteristics; and (iii) it encourages banks to

\footnotetext{
${ }^{15}$ Conceptually, the 30 days calendar period would allow management and supervisors time to take appropriate corrective actions or resolve the bank in an orderly fashion. Furthermore, it would give the central bank additional time to take measures as needed.

${ }^{16}$ The stress scenario assumes both an idiosyncratic and market-wide disruption to liquidity funding markets. See BCBS (2013a), paragraph 19.

${ }^{17}$ Coverage ratios are typically calculated as liquid assets divided by (short-term) liabilities. Before the LCR there was no universal standard coverage ratio methodology, though most jurisdictions used variations of this ratio as an input to liquidity supervision.
} 
strengthen the management of liabilities by differentiating the treatment of liabilities which attract discrete stressed outflow rates.

Implementing the LCR would have several benefits for DEs. These include: (i) a more accurate, forward-looking and risk-sensitive measure of liquidity and funding risk using stressed assumptions; (ii) strengthening the resilience to short-term liquidity shocks; (iii) discouraging reliance on short-term sources of funding; and (iv) encouraging banks to improve liability management.

While the LCR is a more sophisticated approach, design complexity and calibration create a range of policy and implementation issues. Experience suggests that the two main implementation challenges are the availability of HQLA and the calibration of stressed outflows. The LCR introduces strict eligibility criteria for HQLA and, as a result, assets that meet these tests may be scarce in DEs. The other main challenge is the process of segmenting the liability profile to meet LCR definitions and assigning accurate estimates of stressed outflows to each liability category.

Implementation challenges are likely to be more acute for DEs due to their diversity and uniqueness. Applying many of the assumptions underpinning the LCR would present challenges for DEs given their less-mature financial markets and banking systems. For example, in many DEs, the only assets available to meet existing definitions of HQLA are government bonds and cash. Interbank markets are often limited to a small number of participant banks (exacerbated by a dearth of externally rated banks) and there is a lack of secondary market liquidity for securities. The eligibility criteria for HQLA in the LCR is, however, predicated on well-functioning domestic financial systems where high-quality assets can be traded in both good times and under stressed conditions. In reality, while central banks act as the lender of last resort and provide emergency liquidity against government debt to solvent institutions, the LCR requires that banks liquefy HQLA in private markets in the first instance rather than rely wholly on central bank liquidity to fund stressed outflows. ${ }^{18}$

The LCR framework provides several alternatives to help facilitate implementation. The LCR introduces Alternative Liquidity Arrangements, which are three potential options supervisors can use in the event they encounter implementation difficulties, particularly in relation with insufficient supply of HQLA. The three approaches allow possible adaptions to the framework such as: use of a central bank liquidity facility (Option 1), or foreign currency assets to cover domestic currency liquidity needs (Option 2); and additional use of Level 2 assets with a higher haircut (Option 3). These options may provide DEs potential solutions to implementation challenges.

\footnotetext{
${ }^{18}$ As recognized in the LCR framework, HQLA should ideally be eligible at central banks for intraday liquidity needs and overnight liquidity facilities. However, central bank eligibility does not by itself constitute the basis for the categorization of an asset as HQLA. The test of whether liquid assets are of "high quality" is that, by way of sale or repo, their liquidity-generating capacity is assumed to remain intact even in periods of severe idiosyncratic and market stress.
} 
The priority for DEs should be the implementation of robust standards of liquidity risk management. Establishing robust standards of risk management is crucial to ensure the presence of healthy banking systems (see Box 5). The fundamental role of banks in the maturity transformation of short-term deposits into long-term loans makes banks inherently vulnerable to liquidity risk (of an institution-specific nature and that affecting markets as a whole). In response to the liquidity phase of the crisis, the BCBS published a set of minimum expectations for management and supervision of liquidity risk (BCBS, 2008). ${ }^{19}$ The set consists of 14 principles that banks are expected to observe, including Board and Senior Management responsibility for liquidity risk, policies and processes, stress testing, and the need to develop contingency funding plans. Implementation of these principles would go a long way in strengthening management of risk and help achieve consistency with the BCP (Core Principle 24: Liquidity). ${ }^{20}$

DEs should take a careful approach in relation to the LCR and initial focus should be on information gathering and liquidity monitoring. Liquidity information is often scarce and available liquidity indicators may be excessively blunt. A useful starting point to enhance liquidity supervision is to design data templates using the information needed for the LCR and the monitoring tools recommended by the Basel Committee as benchmark. However, DEs could consider simplifying the template by reducing the granularity of information when specific funding sources, liquidity needs, and liquid assets are not relevant in their context.

DEs are encouraged to gain experience with the LCR before imposing it as a minimum requirement. Liquidity risk in DEs differs in some important aspects. Financial institutions, for instance, may rely more on customer deposits for funding. Further, debt markets can be shallow, limiting the availability of liquid assets and deposit insurance may be less widespread (Demirgüç-Kunt and others, 2014). These differences with AEs suggest the need to gain additional experience with the LCR and better assess potential unintended consequences before its formal implementation as a minimum requirement.

DEs should target convergence with the LCR over a time horizon that considers local conditions. Consistent with the experience in countries that have implemented the LCR, implementation needs to be managed at a pace that gives banks and depositors enough time to adjust to changes. Given structural surplus liquidity, many DEs will not have difficulty complying with the 100 percent threshold; however, there are other potential adjustments, such as the development of debt and capital markets and the investment in deposit product systems that are needed to accurately estimate stressed outflows.

\footnotetext{
${ }^{19}$ The Basel Committee conducted a review of "the Sound Principles for Liquidity Risk Management in 2019 and concluded that 'the Sound Principles remain fit for purpose, and the Committee advises banks and supervisors to remain vigilant of liquidity risks in financial markets." See BCBS (2019).

${ }^{20}$ Core Principle 24 relates to liquidity risk and requires that the supervisor sets prudent and appropriate liquidity requirements for banks that reflect the liquidity needs of the bank. For a full explanation of the requirements of the Basel Core Principles for liquidity risk, see BCBS (2012a).
} 


\section{Box 5. Principles for Sound Liquidity Risk Management and Supervision}

The Sound Principles represent a comprehensive framework for bank liquidity risk management containing 17 principles broken into 5 categories (i) fundamental principle; (ii) governance; (iii) measurement and management; (iv) public disclosure; and (v) the role of supervisors.

A bank is responsible for the sound management of liquidity risk (Principle 1). A bank should establish a robust liquidity risk management framework that ensures it maintains sufficient liquidity, including a cushion of unencumbered, HQLA, to withstand a range of stress events. Supervisors should assess the adequacy of a bank's liquidity position and risk management framework and take actions early.

Governance of liquidity risk management (Principles 2-4). A bank should clearly articulate a liquidity risk tolerance appropriate for the business strategy. Senior management should develop strategies, policies and practices to manage liquidity risk within tolerance and be continually reviewed. The Board is ultimately responsible for the liquidity risks assumed by the bank and should review and approve the liquidity strategy, policies and practices. Liquidity costs and benefits should be incorporated into bank internal pricing and performance management and aligned with incentives.

Measurement and management of liquidity risk (Principles 5-12). A bank should have a sound process for identifying, measuring, monitoring, and controlling liquidity risk within and across legal entities, business lines and currencies - taking into account legal, regulatory, and operational limitations to the transferability of liquidity. A bank should establish a funding strategy that provides effective diversification in the sources and tenor of funding. A bank should actively manage its intraday liquidity positions. A bank should actively manage its collateral positions, differentiating between encumbered and unencumbered assets. A bank should conduct stress tests on a regular basis for a variety of short-term and protracted institution-specific and market-wide stress scenarios (individually and in combination). A bank should use stress test outcomes to adjust its liquidity risk management strategies, policies, and positions and to develop effective contingency plans. A bank should have a formal contingency funding plan. A bank should maintain a cushion of unencumbered, HQLA to be held as insurance against a range of liquidity stress scenarios.

Public Disclosure (Principle 13). A bank should publicly disclose information on a regular basis to help market participants make an informed judgement about the soundness of its liquidity risk management framework and liquidity position.

The role of Supervisors (Principles 14-7). Supervisors should regularly perform a comprehensive assessment of a bank's overall liquidity risk management framework and liquidity position to determine whether they deliver an adequate level of resilience to liquidity stress given the bank's role in the financial system. Supervisors should supplement their regular assessments by monitoring a combination of internal reports, prudential reports and market information. Supervisors should intervene early to require effective and timely remedial action by a bank to address deficiencies in its liquidity risk management processes or liquidity position. Supervisors should communicate with other supervisors and public authorities, such as central banks, both within and across national borders, to facilitate effective cooperation regarding the supervision and oversight of liquidity risk management.

Modifications to the LCR framework may be required with a view to reducing variances over time (Appendix II). The wide diversity of financial systems in DEs makes the implementation of a standardized approach to liquidity risk measurement and management challenging. Therefore, modifications in certain areas of the framework may be beneficial to smooth transition. While modification may be necessary initially to achieve implementation across a greater number of jurisdictions, over time the modifications can be rolled back so that the LCR and Net Stable Funding Ratio (NSFR) become the minimum standard for liquidity risk management globally. 
Especially for those DEs hosting globally active banks, greater convergence with the international standards would help promote financial development and support financial stability.

DEs should be mindful of the risk of encouraging excessive concentration of exposures on local sovereign bonds. Shallow financial markets limit the availability of assets that can be considered HQLAs. Often, in domestic currency, these are limited to short term local sovereign bonds. In these circumstances the introduction of the LCR might lead to an increase in exposure to the local sovereign and excessive concentration.

The ease with which government bonds can be converted into cash needs to be considered when defining their eligibility as an HQLA. In principle, the LCR considers that all sovereign bonds are HQLAs. However, in some cases there is no secondary market for some government bonds, which would imply that the clear majority of them would be held to maturity. ${ }^{21}$ In the absence of a secondary market, the question of convertibility to cash hinges on whether banks would be able to post the securities as collateral with the central bank. If some variety of government bonds are not accepted as collateral for central bank operations and there is no meaningful secondary market for them, it might be prudent to restrict their eligibility as HQLAs. ${ }^{22}$

Supervisors should monitor and enforce appropriate liquidity standards by currency. The financial system of some DEs can be highly dollarized. Since banks and supervisors cannot assume that currencies will remain transferable during stress, banks should be expected to maintain liquid assets consistent with the distribution of their liquidity needs by currency.

\section{B. Net Stable Funding Ratio (NSFR)}

The NSFR is designed to enhance long-term resilience of bank funding models, reducing funding mismatches. The NSFR is designed to reduce funding risk over a longer-time horizon by requiring banks to fund their activities with sufficiently stable sources of funding. In this way, the NSFR focuses on the structural funding profile of a bank in order to mitigate the risk of future funding stress. If the NSFR is too low, the average maturity of its liabilities might be too short or on the asset side, banks may hold illiquid assets or assets that are not adequate collateral for secured borrowings.

Implementation of the NSFR may be undertaken after the LCR has been fully embedded. Many of the definitions of assets and liabilities used in the NSFR are taken from the LCR. An often-sensible approach is to ensure that banks are using these definitions consistently and in line with the intent of the regulations before moving into the NSFR. Calibration of factors for available stable funding and required stable funding need to be informed by extensive quantitative analysis of impact on bank liquidity and management of assets and liabilities.

\footnotetext{
${ }^{21}$ Market depth and liquidity is greatest at the short end of the curve for most instruments (sovereign debt included) and this should be taken into consideration.

22 The restrictions could take the form of additional limits and haircuts for illiquid government bonds.
} 
While experience with the NSFR is still accumulating, remediation of an NSFR shortfall may require often far-reaching changes to a bank's balance sheet. There are several potential remediation measures in the event a bank faces an NSFR shortfall e.g., lengthening the maturity profile of liabilities or purchasing additional assets with a low required stable funding factor. As a consequence, in the process of adjusting their funding structure and assets profile to make them compatible with each other, banks might need to change their business models and strategy. As in the case of the LCR, DEs are encouraged to gain experience with the NSFR and fully understand its impact on banks' behavior before imposing it as a minimum requirement.

\section{Box 6. Prudential Regulation and Market Development}

Sustainable financial deepening in DEs can help tackle developmental needs. Financial development can boost economic growth by mobilizing savings, improving resource allocation and facilitating risk management (Levine, 2005). While studies seem to suggest that there is a point that financial development benefits decline while costs rise, most DEs can still benefit from further financial deepening (Sahay and others, 2015).

Policies for achieving financial deepening and greater inclusion should not give rise to undue stability risks. The cost of banking crisis in emerging markets (EM) in terms of output loss is on average 26 percent of GDP (Laeven and Valencia, 2012). Regulation and supervision, including market conduct and consumer protection, must keep pace with financial deepening. After all, as the financial sector expands, market failures can become more pronounced and the impact of crisis higher.

Sacrificing prudence to boost credit in the short term does not pay-off. The regulatory principles that are critical for financial stability also support financial development. Therefore, there should be little or no conflict between safeguarding financial stability and promoting financial development. Furthermore, evidence shows that healthy and stable credit provision is underpinned by resilient and well capitalized banking systems. ${ }^{1}$

Policies to increase financial deepening should focus on improving fundamentals. Lessons from cross-country experiences with financial deepening suggest that targeted and balanced initiatives to encourage competition, develop information and market infrastructure, address collateral issues, and limit excessively intrusive public-sector interventions and dominance, can help overcome specific impediments to financial deepening (IMF, 2012).

${ }^{1}$ See Gambacorta and Marques-Ibanez (2011) for a discussion about credit provision during stress periods and Michelangeli and Sette (2016) for evidence on the supply of mortgages.

\section{Conclusion}

There is no one-size-fits-all strategy to implement the post-crisis banking regulatory standards in DEs. A thoughtful implementation of the post-crisis regulatory standards, which takes into account the specific characteristics of each jurisdiction, enhances banking system resilience in DEs without conflicting with market development needs (Box 6). Differences in financial development, the risk profile of the banking sector, and supervisory capacity need to be considered when establishing the priorities and the best path forward. Adjustments to international standards may be necessary but should observe the guiding principles set out in the introduction of the paper.

\section{A. Prioritizing Implementation}

The post-crisis reforms improved several existing standards, created new tools, and enhanced the macroprudential dimension of banking regulation. All these elements are important components of an effective regulatory framework. The standards address different portfolios and risks and are 
considered relatively independent from one another. Therefore, it is not necessary to fully implement Basel II to implement some innovations brought by Basel III.

Sequencing is an important consideration that needs to be addressed when migrating from Basel I. Given the modular nature of the Basel framework which allows some flexibility in implementation, jurisdictions can consider prioritizing the different elements, accounting for their expected benefits and implementation challenges. In this regard, sequencing becomes an important consideration. Figure 3 provides a stylized example of priorities and sequencing jurisdictions may consider. While all these elements are important components of an effective regulatory framework, it may make sense to prioritize some elements depending upon country-specific factors, e.g., risk profile, supervisory capacity, etc.

\section{Figure 3. Possible Priority for Implementation of Basel III}

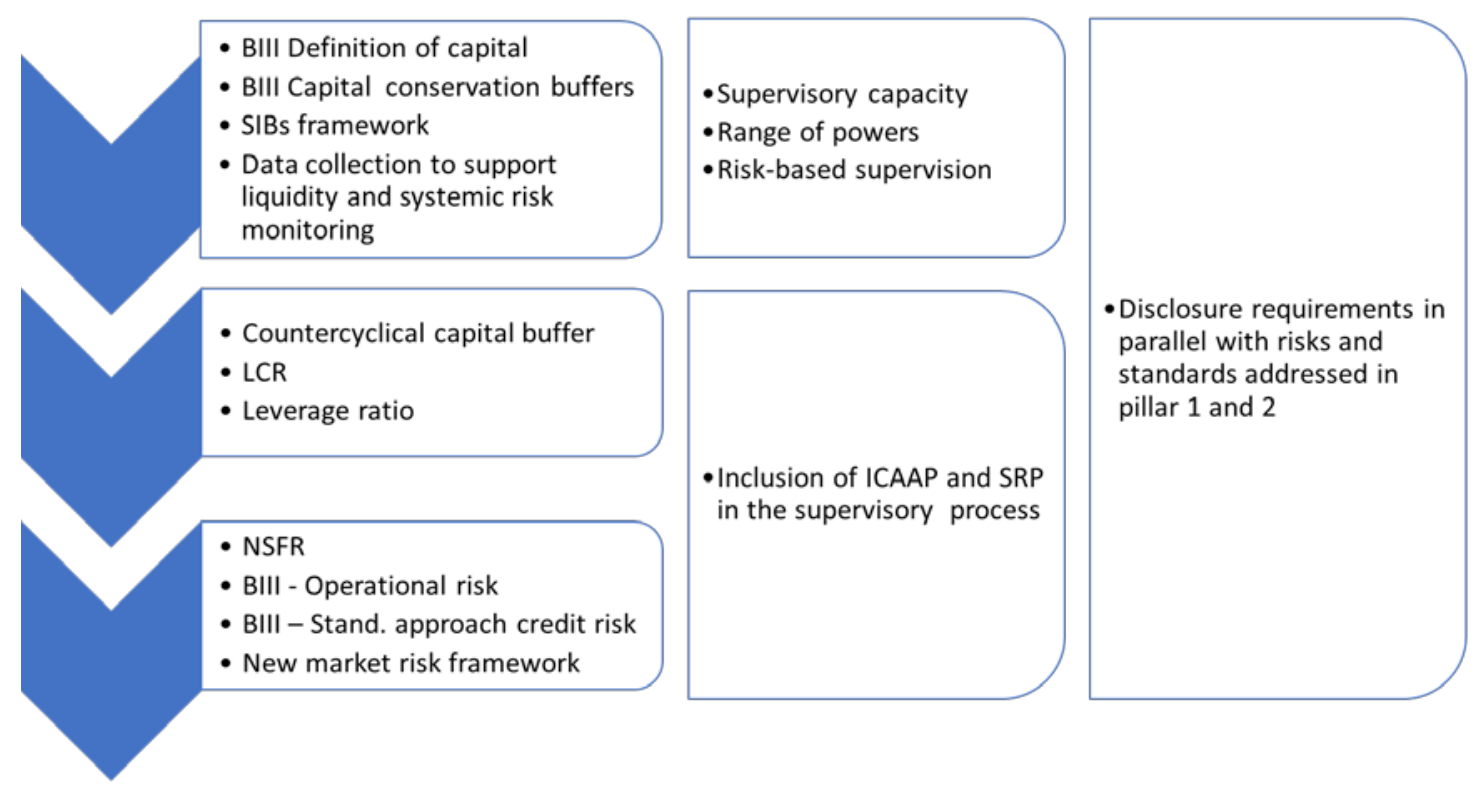

Those standards that are more aligned with the current needs of DEs should be prioritized. DEs are a large and diverse group of countries and specific priorities may differ. It is also important to consider if countries have the preconditions and supervisory capacity to implement some of the regulatory elements. Assuming that countries have implemented Basel I in a reasonably sound way, five elements would often bring the largest benefits to DEs and help set the foundations for more advanced standards:

- implementing the new definition of capital to strengthen the quality of regulatory capital;

- implementing the new capital structure and the capital conservation buffer to differentiate minimum requirements from capital buffers;

- ensuring that SIBs have a capital charge commensurate with the risks and externalities that they pose to the financial system and the economy;

- enhancing data collection to support effective monitoring of systemic risk; and 
- improving information gathering and monitoring of liquidity risk using the LCR/NSFR and the recommended monitoring tools as benchmarks.

Complex tools should be formally adopted after the necessary conditions are met. Tools such as the countercyclical capital buffer require sound data bases, institutional settings and financial system monitoring practices. DEs should focus on ensuring these fundamentals are in place before formally establishing the mechanism. Along the same line, quantitative liquidity standards (LCR/NSFR) need to be carefully calibrated and analyzed for unintended consequences before their complete transposition into regulation.

Improvements on RWA calculation are usually more complex and could be taken in parts. Basel III improved the calculation of RWAs for the three Pillar I risks. Nonetheless, implementation costs are meaningful and benefits can vary substantially across DEs. In this context a possible way forward is to:

- ensure appropriate risk coverage in the capital framework by implementing the operational and market risk charges when exposures are material; and

- improve the risk sensitivity of relevant credit portfolios, including by using variables not prescribed by Basel III but that are important risk drivers in the domestic context; when doing so, it would be key to ensure that the resulting capital requirements are not lower than the international standards.

Pillar 2 implementation should start building a strong foundation in the form of an effective riskbased supervisory approach. It is key to ensure that supervisors have the capacity to assess risks and effectively challenge banks' practices. They should also have the necessary range of powers and institutional arrangements that favor early corrective measures. A strong risk-based and forward-looking supervisory approach would facilitate the implementation of the second pillar and make it more effective. The ICAAP and the supervisory review process should be adopted in a second stage, as an integral part of the risk-based supervision processes.

Pillar 3 should be enhanced in parallel with the risks and international standards incorporated in the regulatory framework. For instance, disclosure requirements associated with the LR should be introduced when the definition and minimum value of the LR are established in the regulation. 


\section{REFERENCES}

Basel Committee on Banking Supervision, 2008, "Principles for Sound Liquidity Risk Management and Supervision," September (Basel: Bank for International Settlements). ,2010, "Guidance for national authorities operating the countercyclical capital buffer," December (Basel: Bank for International Settlements).

, 2011a, "Basel III: A global regulatory framework for more resilient banks and banking systems," June (Basel: Bank for International Settlements).

,2011b, "Principles for the sound management of operational risk," June (Basel: Bank for International Settlements).

,2012a, "Basel core principles for effective bank supervision," September (Basel: Bank for International Settlements).

,2012b, “A framework for dealing with domestic systemically important banks," October (Basel: Bank for International Settlements).

, 2013a, "Basel III: The Liquidity Coverage Ratio and liquidity risk monitoring tools," January (Basel: Bank for International Settlements).

,2013b, "Regulatory Consistency Assessment Program (RCAP) - Analysis of riskweighted assets for market risk," January (Basel: Bank for International Settlements).

,2013c, "Global systemic important banks: updated assessment methodology and higher loss absorbency requirement,” July (Basel: Bank for International Settlements).

, 2013d, "Regulatory Consistency Assessment Program (RCAP) - Analysis of riskweighted assets for credit risk in the banking book," July (Basel: Bank for International Settlements).

, 2013e, "Capital requirements for banks equity investment in funds," December (Basel: Bank for International Settlements).

,2013f, "Principles for effective risk data aggregation and risk reporting," January (Basel: Bank for International Settlements).

,2014a, "Basel III LR framework and disclosure requirements," January (Basel: Bank for International Settlements). 
, 2014b, "Basel III: The net stable funding ratio," October (Basel: Bank for International Settlements).

,2015a, "Revised Pillar 3 disclosure requirements," January (Basel: Bank for International Settlements).

,2015b, "Guidelines for identifying and dealing with weak banks," July (Basel: Bank for International Settlements).

, 2015c, "Corporate governance principles for banks,” July (Basel: Bank for International Settlements).

,2015d, "Margin requirements for non-centrally cleared derivatives," March (Basel: Bank for International Settlements).

,2016, "Minimum capital requirements for market risk," January (Basel: Bank for International Settlements).

,2017a, "Pillar 3 disclosure requirements - consolidated and enhanced framework," March (Basel: Bank for International Settlements).

, 2017b, “Basel III: Finalising post-crisis reforms," December (Basel: Bank for International Settlements).

, 2017c, "Pillar III disclosure requirements - consolidated and enhanced framework," March (Basel: Bank for International Settlements).

,2017d, "Prudential treatment of problem assets - definition of non-performing exposures and forbearance," April (Basel: Bank for International Settlements).

,2018, "Capital treatment for simple, transparent and comparable short-term securitization," May (Basel: Bank for International Settlements).

, 2019a, "Minimum capital requirement for market risk," January (Basel: Bank for International Settlements).

,2019b, "Basel Committee completes review of principles for sound liquidity risk management and supervision,” January (Press Release Basel: Bank for International Settlements). 
Carvalho, A., S. Hohl, R. Raskopf and S. Ruhnau, 2017, "Proportionality in banking regulation: a cross-country comparison,” FSI Insights, August (Basel: Bank for International Settlements).

Dell'Arricia, Giovanni, Caio Ferreira, Nigel Jenkinson, Luc Laeven, Alberto Martin, Camelia Minoiu, and Alex Popov, 2018, "Managing the Sovereign Bank Nexus," IMF Departmental Paper 18/16 (Washington: International Monetary Fund).

Demirgüç-Kunt, Asli, Edward Kane, and Luc Laeven, 2014, “Deposit Insurance Database,” IMF Working Paper 14/188 (Washington: International Monetary Fund).

Fender, I., and U. Lewrick, 2015, “Calibrating the LR,” BIS Quarterly Review, December 2015, pp 43-58.

Financial Stability Board, 2009, "Principles for Sound Compensation Practices," April (Basel: Bank for International Settlements). ,2010, "Intensity and Effectiveness of SIFI Supervision: Recommendations for Enhanced Supervision," November (Basel: Bank for International Settlements).

, 2013, “An Overview of Policy Recommendations for Shadow Banking,” August (Basel: Bank for International Settlements). , 2014, "Key Attributes of Effective Resolution Regimes for Financial Institutions," October (Basel: Bank for International Settlements). , 2017a, "Policy Recommendations to Address Structural Vulnerabilities from Asset Management Activities," January (Basel: Bank for International Settlements).

, 2017b, Review of OTC derivatives market reforms. June (Basel: Bank for International Settlements).

, 2017c, "Implementation and Effects of the G20 Financial Regulatory Reforms," July (Basel: Bank for International Settlements). , 2017d, "Guidance on Central Counterparty Resolution and Resolution Planning," July (Basel: Bank for International Settlements).

Gambacorta, L., and D. Marques-Ibanez, 2011, "The banking lending channel: Lessons from the crisis,” BIS Working Paper 345, May 2011. 
Goyal, R., et al., 2011, "Financial Deepening and International Financial Stability," IMF Staff Discussion Note 11/16, October, 2011.

Hohl, S., M.C. Sison, T. Stastny, and R. Zamil, 2018, "The Basel Framework in 100 jurisdictions: implementation status and proportionality practices," FSI Insights on policy implementation No 11, November (Basel: Bank for International Settlements).

International Monetary Fund, 2010, "The Making of Good Supervision: Learning to Say "No"," Staff Position Note 10/08, May (Washington: International Monetary Fund). , 2012, "Enhancing Financial Sector Surveillance in Low-Income Countries: Financial Deepening and Macrostability,” IMF Policy Paper, April (Washington: International Monetary Fund). , 2014a, "Staff Guidance Note on Macroprudential Policy," December (Washington: International Monetary Fund). , 2014b, "Staff Guidance Note on Macroprudential Policy—Detailed Guidance on Instrument" December (Washington: International Monetary Fund). , 2014c, "Staff Guidance Note on Macroprudential Policy —Considerations for Low Income Countries," December (Washington: International Monetary Fund).

Levine, Ross, 2005, "Finance and Growth: Theory and Evidence," In Handbook of Economic Growth, edited by Philippe Aghion and Steven Durlauf, New York: Elsevier: 865-934.

Michelangeli, V. and E. Sette, 2016, "How Does Bank Capital Affect the Supply of Mortgage? Evidence from a Ramdomized Experiment," BIS Working Paper 557, April 2016.

Sahay, R., and others, 2015, "Rethinking Financial Deepening: Stability and Growth in Emerging Markets," IMF Staff Discussion Note 15/08, May 2015.

Strahan, Philip E., 2012, "Liquidity Risk and Credit in the Financial Crisis," FRBSF Economic Letter, May. 


\section{Appendix I. Prudential Standards Implementation Steps}

An indicative roadmap for the implementation of prudential standards (intended to be a sequenced approach) is set out below:

a. Draft regulation establishing (or reviewing) the prudential standard and guidance on any changes that are being proposed to other regulations or protocols.

b. Draft supervisory reporting templates associated with new (revised) standard.

c. Establish a supervisory/industry working group.

d. Publish draft regulation for consultation. ${ }^{1}$

e. Conduct a QIS workshop with banks to provide instruction on the new standard and seek views where clarification might be required.

f. Establish a reporting database.

g. Conduct a QIS. Detailed guidance should accompany the QIS with a single point of contact for queries. The QIS submission should be accompanied with a reconciliation back to prudential returns and the balance sheet.

h. Analyze and interpret QIS results, including feedback meetings with banks.

i. Refine draft framework (regulation, guidance, and reporting templates publication and consultation); if revisions to the draft are meaningful, a new QIS may be necessary.

j. Design phase-in and other transitional arrangements.

k. Publish final rules and any other amended regulations.

1. Align relevant regulatory reporting to new standard methodology.

m. Initiate parallel run period and work with banks to improve data quality.

\footnotetext{
${ }^{1}$ See Gambacorta and Marques-Ibanez (2011) for a discussion about credit provision during stress periods and Michelangeli and Sette (2016) for evidence on the supply of mortgages.
} 


\title{
Appendix II. Guiding Principles for Modifying LCR and Main Issues
}

\begin{abstract}
A. Assets
Chief among the modifications to the LCR framework is the need to adopt a pragmatic approach to HQLA eligibility. The strict application of the LCR framework requires supervisors to apply the market liquidity test to assets eligible as HQLA. ${ }^{2}$ The objective is to ensure that banks hold assets that can be monetized in private markets in the first instance, but that ultimately if private markets fail, the assets can be repo'ed with the central bank. The framework does not permit central bank repo eligibility by itself to be counted as HQLA, which is a significant change from many existing coverage ratio regimes across DEs. It is likely that the thinness of EMDE markets will mean that a private market is unavailable for most assets in a stress scenario and a strict application of the market and fundamental characteristics will render ineligible sovereign and other securities in DEs. To ease implementation, the market liquidity test should be relaxed for sovereign bonds as a practical solution to the scarcity of liquid assets that meet the LCR definition of HQLA.
\end{abstract}

\section{The market and fundamental tests should be retained for Level 2 assets, but with a view to developing financial markets as a long-term solution to expanding the availability of} HQLAs. Jurisdictions looking to implement the LCR should also pursue a policy of broad-based financial sector development as an important condition for the sustainability and durability of the framework to liquidity risk management, when needed. The greater the diversity of liquid assets in the portfolio of HQLAs, the less reliance there is on the central bank as the assets can be monetized in a stress in the private markets. Therefore, policies that encourage a deepening of financial markets in DEs are helpful to broaden the availability of securities that meet the LCR definition of an HQLA. The development of financial markets will help break down the sovereign bank loop that exists and ensure private markets are used to absorb liquidity shocks before the central banks provides liquidity as lenders of last resort.

\section{B. Liabilities}

To address the challenges of accurately estimating stressed outflow assumptions for liabilities, applying a standardized approach is a potential solution. For many EMDE banks, liabilities are typically treated as a homogenous pool: the majority of which are customer deposits that have a short-term contractual maturity, i.e., at call. As a result, a granular approach to estimating run-off rates for discreet pools of deposit with a level of certainty - as prescribed by the LCR framework - is inherently difficult. A practical solution is to assign a standardized run-off rate to customer deposits (i.e., retail and SME deposits, such as 10 percent), permitting a differential treatment in exceptional cases where the bank can demonstrate alignment with the LCR definitions. Furthermore, there is a need to more frequently revise and update run-off

\footnotetext{
${ }^{2}$ The LCR applies three tests for assets to be eligible as HQLA, including: fundamental characteristics, marketrelated characteristics and operational requirements. These factors are intended to assist supervisors in determining which assets are sufficiently liquid in private markets to be included in the stock of HQLA.
} 
assumptions owing to the rapidly changing financial markets in DEs. In this sense, historical runoff rates and assumptions about customer behavior may not be a close proxy for actual or expected stressed outflows. (Figure A1 sets out a decision tree to help determine run-off rates for retail deposits.)

The starting point for classifying depositors should default to the "less stable" outflow rate. It is questionable whether the minimum run-off rates prescribed by the LCR are applicable for DEs. A generally conservative calibration of weighted liabilities is suggested and to preserve this conservatism, the supervisors should classify customer deposits as "less stable" as a floor which has a higher minimum outflow than the "stable" category. The run off rates for "stable" retail deposits in the LCR framework attract a very low run-off rate of 5 percent (and lower if deposit guaranteed), which may not be appropriate given the nature of the deposit market, absent deposit insurance, and other factors. ${ }^{3}$

\section{Seven characteristics should be used as a minimum as examples that would determine} whether deposits fall into either the "stable" or "less stable" buckets (BCBS, 2013a).

Regarding retail deposits, these characteristics are: (i) not covered by deposit insurance; (ii) highvalue deposits; (iii) lack of established relationship; (iv) internet-only savings accounts; (v) high net worth; (vi) withdrawn quickly; and (vi) foreign-exchange denominated deposits.

The calibration of run-off rates should be informed by results from a QIS exercise. Calibration of run-off rates is crucial and the QIS exercise will be a key step in determining the treatment of liabilities, especially given the considerable differences between the minimum runoff assumptions in the LCR framework and the experience of DEs. The estimates in the LCR framework should not be seen as the de facto minimum. Instead the calibration of run-off rates should reflect the features of the local deposit market and historical behavior under stressed assumptions.

\footnotetext{
${ }^{3}$ Application of the 3 percent run off rate under the LCR needs to satisfy several conditions, such as: classified as stable, a fully funded deposit insurance scheme is in place, and historical run-off rates support the estimate (BCBS, 2013a). The 3 percent run off rate for retail deposits should not be seen as the de facto minimum.
} 
Figure A1. Decision Tree for Classification of Retail Deposits

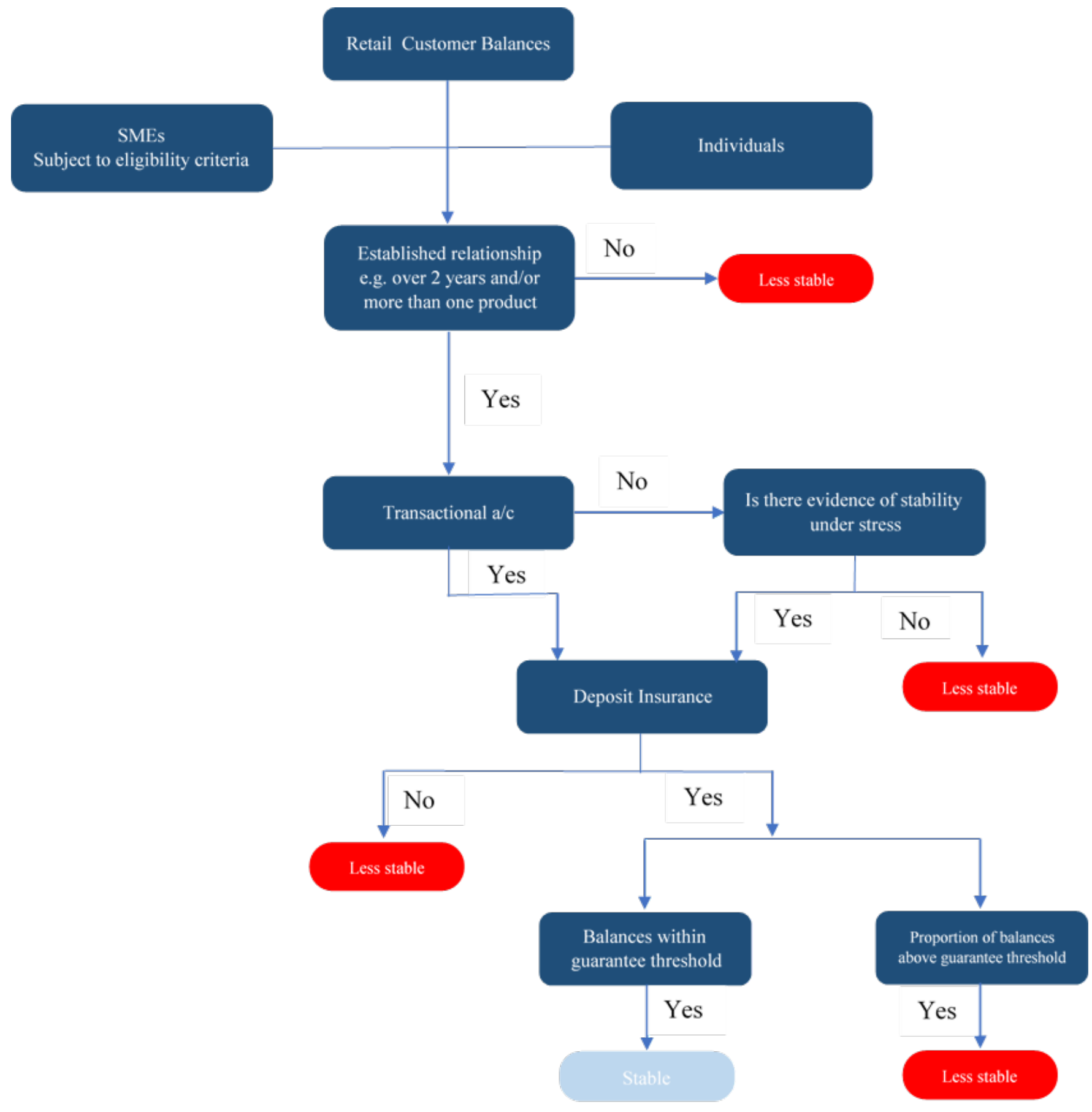

Source: IMF staff. 